\title{
Review \\ Long Non-Coding RNAs as Functional Codes for Oral Cancer: Translational Potential, Progress and Promises
}

\author{
Cing-Syuan Lei ${ }^{1}$, Hsing-Jien Kung ${ }^{1,2,3,4,5}$ and Jing-Wen Shih $1,2,5,6, *$ CD \\ 1 Ph.D. Program for Cancer Molecular Biology and Drug Discovery, College of Medical Science and \\ Technology, Taipei Medical University and Academia Sinica, Taipei 11031, Taiwan; \\ m507102013@tmu.edu.tw (C.-S.L.); hkung@tmu.edu.tw (H.-J.K.) \\ 2 Graduate Institute of Cancer Biology and Drug Discovery, College of Medical Science and Technology, \\ Taipei Medical University, Taipei 11031, Taiwan \\ 3 Institute of Molecular and Genomic Medicine, National Health Research Institutes, Zhunan, \\ Miaoli County 35053, Taiwan \\ 4 Comprehensive Cancer Center, Department of Biochemistry and Molecular Medicine, \\ University of California at Davis, Sacramento, CA 95817, USA \\ 5 TMU Research Center of Cancer Translational Medicine, Taipei Medical University, Taipei 11031, Taiwan \\ 6 Ph.D. Program for Translational Medicine, College of Medical Science and Technology, \\ Taipei Medical University, Taipei 11031, Taiwan \\ * Correspondence: shihjw@tmu.edu.tw
}

Citation: Lei, C.-S.; Kung, H.-J.; Shih, J.-W. Long Non-Coding RNAs as Functional Codes for Oral Cancer: Translational Potential, Progress and Promises. Int. J. Mol. Sci. 2021, 22, 4903. https://doi.org/10.3390/ ijms22094903

Academic Editor: Thomas Andl

Received: 28 March 2021

Accepted: 3 May 2021

Published: 5 May 2021

Publisher's Note: MDPI stays neutral with regard to jurisdictional claims in published maps and institutional affiliations.

Copyright: (c) 2021 by the authors. Licensee MDPI, Basel, Switzerland. This article is an open access article distributed under the terms and conditions of the Creative Commons Attribution (CC BY) license (https:// creativecommons.org/licenses/by/ $4.0 /)$.

\begin{abstract}
Oral cancer is one of the leading malignant tumors worldwide. Despite the advent of multidisciplinary approaches, the overall prognosis of patients with oral cancer is poor, mainly due to late diagnosis. There is an urgent need to develop valid biomarkers for early detection and effective therapies. Long non-coding RNAs (lncRNAs) are recognized as key elements of gene regulation, with pivotal roles in various physiological and pathological processes, including cancer. Over the past few years, an exponentially growing number of IncRNAs have been identified and linked to tumorigenesis and prognosis outcomes in oral cancer, illustrating their emerging roles in oral cancer progression and the associated signaling pathways. Herein, we aim to summarize the most recent advances made concerning oral cancer-associated lncRNA, and their expression, involvement, and potential clinical impact, reported to date, with a specific focus on the lncRNA-mediated molecular regulation in oncogenic signaling cascades and oral malignant progression, while exploring their potential, and challenges, for clinical applications as biomarkers or therapeutic targets for oral cancer.
\end{abstract}

Keywords: oral cancer; long non-coding RNA; tumorigenesis; cancer progression; metastasis

\section{Introduction}

Oral cancer, one of the most common malignancies worldwide and a leading cause of mortality in certain regions, is currently a major public health issue. According to updated statistics, there was an estimated incidence of 377,000 oral cancer cases and 177,000 deaths worldwide in 2020, with a particularly high frequency in South Central Asia and Melanesia [1]. As the most common cancer developing in the head and neck region [2], oral cancer is comprised of malignancies occurring in the lips, front two-thirds of the tongue, alveolar ridge and gums, floor of the mouth, hard palate, retromolar trigone, and buccal mucosa [3,4]. Over $90 \%$ of oral malignant tumors originate from the squamous cells [5-7] and are collectively known as oral squamous cell carcinoma (OSCC), which can be further divided into three different subsites: buccal mucosal SCC (BMSCC), tongue SCC (TSCC), and lip SCC (LSCC). Several risk factors account for the development of oral cancer, including continuous consumption of tobacco, alcohol, or betel nut, and infection with human papilloma virus (HPV) [8]. Currently, surgery, radiation therapy, and chemotherapy are the standard primary treatments for oral cancer. Despite the advent of multidisciplinary approaches, the prognosis of advanced stage oral cancer patients is still poor, and the 
overall survival rate within five years remains at around 30-50\% [9], mainly due to the high tendency for local recurrence, treatment resistance, and thereafter regional lymph node metastasis. At present, visual screening combined with tissue biopsy is the most common screening approach for oral cancer, but this may provide insufficient information, which results in under-diagnosis and improper care [10]. In addition, the invasive nature, high cost, site-specificity, and limited technique sensitivity make biopsy unsuitable for follow-up purposes. Meanwhile, the heterogenicity of oral cancer at the molecular level hampers the characterization of specific therapeutic targets, resulting in challenges for treatment development. Thus, an in-depth understanding about the molecular mechanisms of oral carcinogenesis and progression is an urgent priority for developing valid biomarkers for early detection and patient stratification, as well as effective therapies against oral cancer [11].

In the human genome, it has now been recognized that protein-coding transcripts represent only a tiny fraction of the transcriptional output (less than 3\%), whereas the majority of transcripts encode a variety of non-coding RNAs. Among the non-coding transcripts, long non-coding RNAs (lncRNAs) are a large family of heterogeneous regulatory RNA molecules longer than 200 nucleotides and without evident protein coding potential [12,13]. According to the most updated human genome annotation (GRch38, GENCODE Release 37; www.gencodegenes.org; accessed on 15 February 2021), 48,741 transcripts originating from 17,948 loci were identified as lncRNAs. LncRNAs can be further sub-divided by their biogenesis loci, including lincRNAs (long intergenic RNAs), long intronic RNAs, eRNAs (enhancer RNAs), asRNAs (antisense RNAs), promoter RNAs, and bidirectional RNAs [14,15]. Similarly to mRNAs, most lncRNA species are transcribed by RNA polymerase II and then capped at $5^{\prime}$ ends and polyadenylated at $3^{\prime}$ ends, as well as spliced and processed. While an increasing number of lncRNAs have been identified in recent years, a steadily growing list of lncRNAs have been characterized as biochemically versatile regulators in different stages of gene expression. At epigenetic, transcriptional, and post-transcriptional levels, through interaction with other bio-macromolecules, such as chromatin DNA, RNA, and proteins, a series of lncRNAs have been shown to be capable of regulating chromatin remodeling, as well as RNA splicing, stability, modification, and translation, by acting as decoy, signals, guides, scaffolds, and sponges $[13,16]$. With such critical multi-functional roles in gene regulation, it is not surprising that an expanding number of dysregulated lncRNAs have been associated with cancer and demonstrated to be the driving force of malignant transformation or suppression.

Over the last few years, the advent of high-throughput sequencing techniques has enabled identification of a continuously rising amount of dysregulated lncRNAs associated with oral cancer $[17,18]$. Among these transcripts, only a few have been thoroughly investigated for their mechanisms of action, whereas the functional details of most remain largely uncharacterized [19-22]. Within the long-standing intense debate about the functionality of most, if not all, of these lncRNAs, a precursor-product relationship between junk RNA and functional lncRNAs has recently been suggested, in which junk transcripts may provide the raw material for the evolution of diverse lncRNAs, through a non-adaptive mechanism [23]. Overall, it is estimated that at least $87 \%$ of the transcribed regions of the human genome DNA generate junk RNAs [23]. Along these lines, most unannotated lncRNAs overexpressed in oral cancer could be simply junk transcripts produced from the accelerated transcription of tumor cells. The clinical relevance and functionality of these so-called junk lncRNAs await future investigation. Notably, the aberrant expression of numerous oral cancer-associated lncRNAs has been significantly linked to the clinicopathological features and survival outcomes of patients, revealing that functional annotation of these transcripts may eventually lead to the development of early diagnosis and new avenues for oral cancer treatment. In the present review, we aim to provide a systematically updated overview of the current knowledge about oral cancer-associated lncRNAs, summarizing their dysregulation and the potential mechanisms (Table 1 and Figure 1), and with a specific emphasis on the functional involvement of these lncRNA 
species in pivotal oncogenic signaling pathways (Figure 2) and the perspectives of these lncRNAs for possible clinical applications.

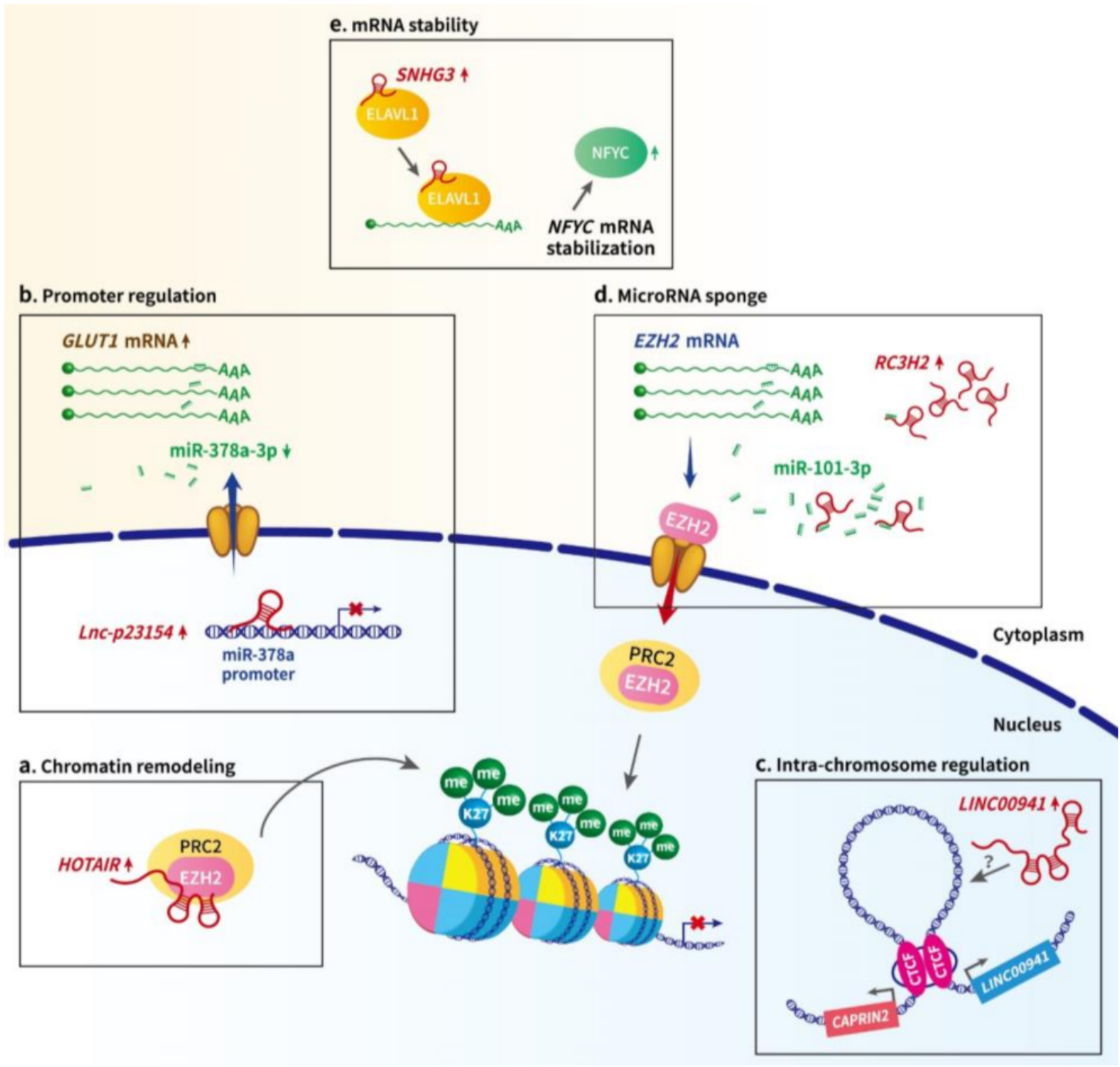

Figure 1. The potential actionmechanisms of lncRNAs in oral cancer. (a) Chromatin remodeling. LncRNA HOTAIR has been recognized as a scaffold interacting with chromatin modifying complexes PRC2 and LSD1 to epigenetically regulate gene expression. In OSCC, HOTAIR knockdown decreased the enrichment of EZH2 (the component of PRC2 complex) and H3K27me3 deposition within the E-cadherin promoter, suggesting HOTAIR could modify chromatin accessibility through recruiting chromatin modifying complex at the transcribed genomic locus. (b) Promoter regulation. Nuclear $\operatorname{lncRNA}$ $\operatorname{lnc}-p 23154$ has been demonstrated to suppress miR-378a-3p transcription by interacting with its promoter region, thereby upregulating the expression of the miR-378a-3p targeted gene, GLUT1, and promoting Glut1-mediated OSCC metastasis. (c) Intra-chromosomal interactions. Through dimerization, transcription factor CTCF could mediate chromatin looping between its binding sites and thereby modulate transcription. LncRNA LINC00941 could activate the expression of its nearby gene CAPRIN2 through CTCF-mediated DNA looping of the specific region between the two genes. (d) miRNA sponge/ceRNA. LncRNA RC3H2 could function as a miRNA sponge by physically binding miR-101-3p, whose target is $E Z H 2$ mRNA. The upregulated EZH2 subsequently suppresses the expression of the downstream gene CDKN2A, facilitating the malignant behavior of OSCC cells. (e) mRNA stability. LncRNA-SNHG3 is able to increase NFYC mRNA stability through interacting with RNA-binding protein ELAVL1, also known as HuR, thereby increasing NFYC protein levels. 


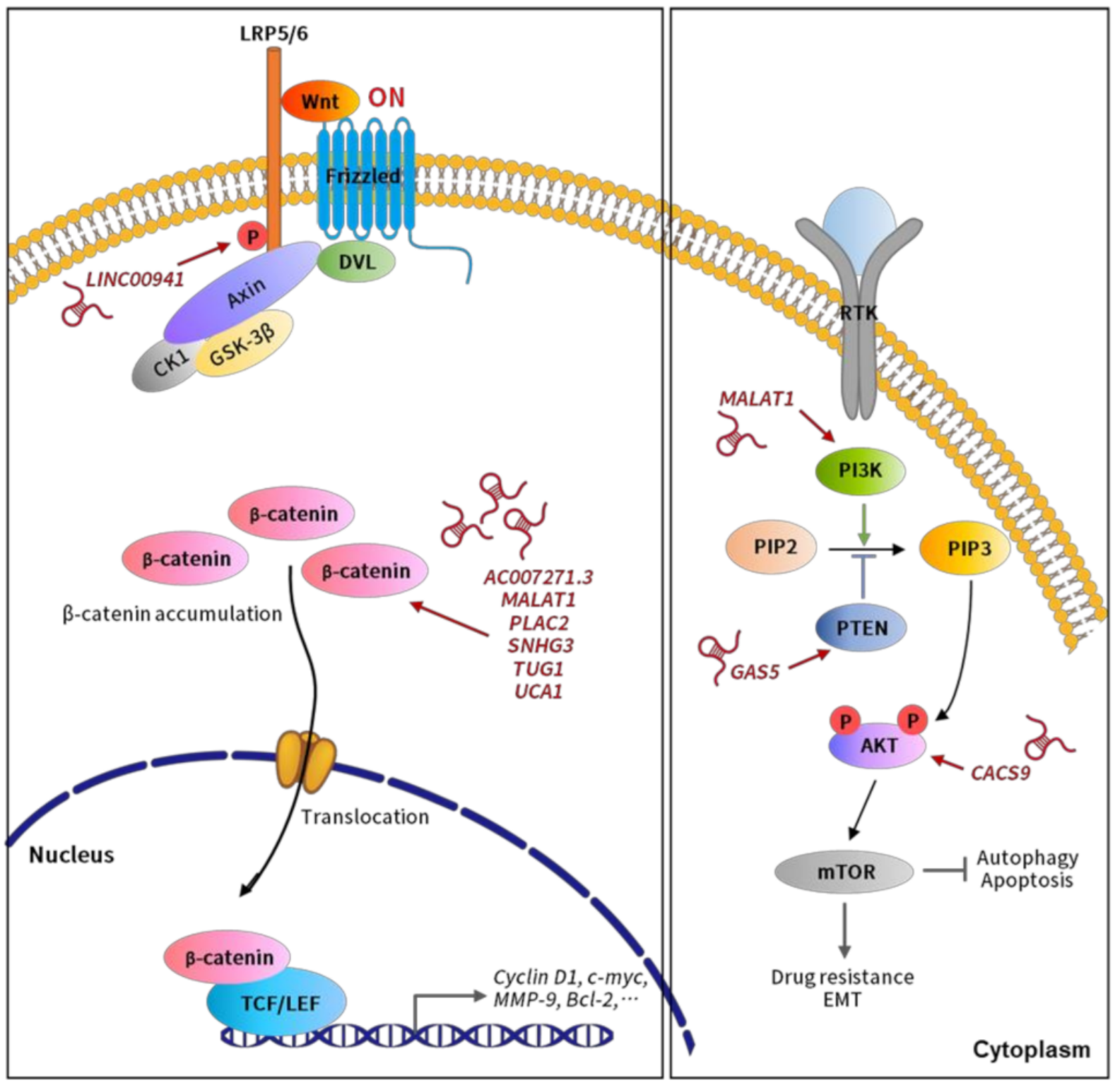

Figure 2. LncRNAs involved in the relevant signaling pathways implicated in oral cancer progression. (a) Wnt/ $\beta$ catenin signaling. LncRNAs, such as AC007271.3, MALAT1, PLAC2, SNHG3, TUG1, and UCA1, could activate Wnt/ $\beta$ catenin signaling mainly through inducing $\beta$-catenin accumulation. The increased $\beta$-catenin would further translocate into the nucleus and bind to LEF/TCF transcription factors to activate the downstream effectors, promoting the malignant behavior of oral cancer cells. In addition, lncRNA LINC00941 could induce the expression of Caprin-2, which further promotes the phosphorylation of the Wnt co-receptor LRP6, and thereby activating Wnt/ $\beta$-catenin signaling. (b) PI3K/AKT/mTOR signaling. Several lncRNAs are able to target the different components of the PI3K/AKT/mTOR pathway to affect oral cancer progression. Overexpression of lncRNA MALAT1 could increase the phosphorylation of PI3K to induce PI3K/AKT/mTOR signaling, thereby promoting the EMT and cisplatin resistance of OSCC. Another lncRNA GAS5 could suppress the malignant behavior of OSCC by serving as ceRNA to sequester miR-21 and thereby reverting the miR-21-mediated repression of PTEN, a negative regulator of PI3K signaling. In addition, lncRNA CASC9 could enhance cell proliferation by inhibiting autophage-mediated cell apoptosis via inducing AKT phosphorylation and the subsequent activation of the AKT/mTOR pathway in OSCC. 


\section{Mechanism of Oral Cancer-Associated lncRNAs in Tumorigenesis}

Tumorigenesis is a complicated multifaceted process that involves three major stages: initiation, progression, and metastasis. Notably, in the past decade, accumulating studies have shown that a series of oral cancer-associated lncRNAs are closely connected to each step of tumorigenesis through their multiple regulatory roles in gene regulation, at various stages, such as chromatin remodeling, transcription activation, RNA interference, and RNA splicing, as well as post-translational control. Table 1 presents an updated list of these oral cancer-associated lncRNAs. In tumor tissues, most oral cancer-associated lncRNAs are significantly up-regulated, whereas C5orf66-AS1 [24], CASC2 [25-27], ENST00000470447.1 [28], FALEC [29], LINC01315 [30], and MORT [31] are among the few which are down-regulated in oral cancer tissues. Although the mechanistic details might remain unclear, most of the oral cancer-associated lncRNAs have an impact on the oral tumorigenesis process. Table 1 summarizes their potential molecular targets along with their reported functions. Notably, several of them, including ANRIL, CASC2, CCAT1, FGD5-AS1, LnCHIFCAR, HOTAIR, HOTTIP, HOXA11-AS, MALAT1, MCM3AP-AS1, MEG3, OIP5-AS1, PVT1, SNHG20, SNHG3, TUG1, and UCA1, might adopt more than one action mode. For the sake of conciseness, a few selected oral cancer-associated lncRNAs are enumerated below to illustrate their mechanisms of actions.

\subsection{LncRNA-Mediated Epigenetic and Transcriptional Regulation in Oral Cancer}

Chromatin remodeling is a complicated process, dynamically altering nucleosome structure by modification of the chromatin architecture to modulate access of genomic DNA to the transcription machinery during gene expression control of the eukaryotic genome. Among various nucleosome remodeling modifications, histone modifications have been functionally linked to epigenetic gene regulation. To date, two lncRNAs, HOTAIR (HOX transcript antisense RNA) and FALEC (focally amplified long non-coding RNA in epithelial cancer), have been proposed to impact the histone modification and transcriptional state in OSCC $[29,32]$. HOTAIR is an oncogenic molecule in a variety of cancers, and functions as a molecular scaffold connecting the histone modification complexes PRC2 (polycomb repressive complex 2) and LSD1 (lysine specific demethylase 1), thereby regulating gene expression via modulation of histone modifications [33,34]. In OSCC cells, Wu et al. found that HOTAIR could repress E-cadherin expression, whereas HOTAIR knockdown would impair the binding of EZH2 (the functional enzymatic component of PRC2) and H3K27me3 within the E-cadherin promoter, suggesting HOTAIR suppresses E-cadherin expression partly through associating with EZH2 [32] (Figure 1a). Subsequent studies further demonstrated that the upregulation of HOTAIR is closely associated with the progression and poor prognosis of OSCC patients [32,35-37]. As another example, in TSCC, the tumor suppressive lncRNA FALEC could recruit EZH2 at the promoter regions of the oncogene ECM1 (extracellular matrix protein 1), epigenetically repressing ECM1 expression, and thereby repressing malignant behaviors [29].

Beyond histone modifications, a possible IncRNA-mediated crosstalk between chromatin organizer and transcription machinery has also been proposed. The DNA-binding protein CTCF (CCCTC-binding factor) is a key player in chromatin organization. By homodimerization of the CTCF proteins and working together with cohesin, CTCF is thought to regulate DNA looping and mediate the 3D structure of chromatin. Recent studies have shown that lncRNAs can regulate gene expression by altering the chromatin architecture or driving the eviction of architectural proteins, including CTCF [38]. In OSCC, Ai et al. demonstrated that oncogenic LINC00941 is highly upregulated due to EP300-driven transcriptional activation, through enhancing H3K27ac deposition within its promoter. Most notably, upregulated LINC00941 could in turn activate the expression of its nearby gene CAPRIN2, whereas chromatin organizer CTCF was required for this LINC00941-induced CAPRIN2 overexpression. As CTCF has been shown to mediate the looping of the chromatin fragment between LINC00941 and CAPRIN2 genes through its binding sites being 
enriched within this region, these results suggested that LINC00941 might induce CAPRIN2 expression through CTCF-mediated DNA looping [39] (Figure 1b).

In addition, IncRNAs have been shown to transcriptionally modulate the tumorigenesis of OSCC through their interactions with DNA or protein molecules. Wang et al. demonstrated that the lncRNA $\operatorname{lnc}-p 23154$, which is mainly localized in the nucleus, suppresses miR-378a-3p transcription via binding to the miR-378a-3p promoter (Figure 1c). As miR-378a-3p could repress Glut1 expression by targeting its $3^{\prime} U T R$, the lnc-p23154mediated miR-378a-3p downregulation consequently leads to increased Glut1 expression and glycolysis, which in turn accelerates OSCC metastasis [40]. Meanwhile, Zhu et al. found that, in OSCC cells, lncRNA HAS2-AS1 (hyaluronan synthase 2 antisense 1) could promote hypoxia-induced cancer progression via inducing the expression of HAS2 (hyaluronan synthase 2) [41]. Since an RNA-DNA interaction between the HAS2-AS1 and HAS2 genes has been reported previously [42], these findings suggested the binding of HAS2-AS1 to HAS2 gene is necessary for HAS2 upregulation. However, whether or not some other chromatin modifiers could cooperate with this RNA-DNA structure to elicit epigenetic modifications remains to be investigated.

Moreover, in our previous report, hypoxia-induced lncRNA LncHIFCAR (long noncoding HIF- $1 \alpha$ co-activating RNA; also named as MIR31HG) was found to directly interact with HIF- $1 \alpha$, which in turn facilitated the formation and recruitment of HIF-1 complex to the promotor region of metastasis-driving genes, and thereby promoting their transcription, as well as OSCC progression [43]. Several lines of evidence in our current study revealed the participation of some other histone modifiers in LncHIFCAR-mediated HIF-1 co-activation (unpublished data), which warrants further investigation. Moreover, in LSCC, other than HIF-1 $\alpha, M I R 31 H G$ was demonstrated to target $\mathrm{p} 21$ to promote the tumorigenic process through an uncharacterized mechanism [44]. Consistent with the above findings, these studies collectively noted that MIR31HG/LncHIFCAR could serve as a poor prognostic factor and putative therapeutic target in HNSCC [43-45].

\subsection{LncRNA-Mediated Post-Transcriptional Regulation in Oral Cancer}

Recent studies have validated that a set of lncRNAs can collaborate with mRNAs or pre-mRNAs to form "lncRNA-mRNA pairs" and consequently fine-tune the mRNA splicing or stability $[46,47]$. In OSCC tissues, Guo et al. identified a highly upregulated lncRNA CEBPA-AS1 (also known as LOC80054) as a potential oncogene and a prognostic biomarker, the expression of which correlates with poor differentiation, lymph node metastasis, and high clinical stage [48]. CEBPA-AS1 knockdown inhibited the tumorigenesis of OSCC by reducing the expression of its nearby gene, CEBPA. Mechanistically, CEBPA$A S 1$, which is predominantly localized in the cytoplasm and the perinuclear region, was found to interact with CEBPA mRNA directly, suggesting that CEBPA-AS1 may induce CEBPA expression in cis through this unique "IncRNA (CEBPA-AS1)-mRNA (CEBPA)" pairing [48]. However, the mechanistic details still need to be elucidated.

Furthermore, the hypothesis of competing endogenous RNA (ceRNA) proposed by Salmena et al. in 2011 [49] has generated substantial interest in uncovering IncRNA function through the ceRNA mechanism. Indeed, some abundant lncRNAs harboring miRNAcomplementary sites are able to modulate gene expression as ceRNAs or "miRNA sponges", thereby sequestering miRNAs and neutralizing the miRNA-mediated negative regulatory effects on their target RNAs [13]. However, the stoichiometric relationship between a miRNA and its target sites presented on the potential competitive endogenous lncRNA is critical for achieving a measurable effect on target-mRNA expression [50-52]. Recently, a large number of lncRNAs have been reported to function as miRNA sponges, reducing miRNA availability to target mRNAs in OSCC. For example, by multi-transcriptome analysis, bioinformatics analysis, and qRT-PCR, Wu et al. validated a co-expression network among lncRNA RC3H2, EZH2, and miR-101-3p. Notably, the cytoplasmic abundant lncRNA, RC3H2, could physically interact with miR-101-3p, while suppression of miR-101$3 p$ could attenuate the lncRNA RC $3 H 2$ knockdown-induced inhibitory effects on OSCC 
cells by targeting EZH2, revealing that lncRNA $R C 3 H 2$ could act as ceRNA to up-regulate EZH2 expression by sponging miR-101-3p (Figure 1d), which subsequently affected the level of H3K27me3 deposition and the expression of downstream genes associated with cancer progression [53,54]. Moreover, the MEG3 [55], ANRIL [56], FGD5-AS1 [57], H19 [58], HOTAIR [37], LINC01315 [30], MALAT1 [59], PDIA3P [60], RBM5-AS1 [61], SNHG20 [33], TUG1 [62], and TTN-AS1 [63] lncRNAs were reported to have the ability to physically interact with miRNAs and thereby influence the development of OSCC. Considering the requirements for appropriate experimental manipulations [52], such as the well-controlled overexpression of miRNAs within physiological ranges and additional evidence supported by miRNA suppression experiments to avoid the potential saturation of RISC complexes, the claims of ceRNA interactions may require more critical evaluation.

Notably, through interaction with a variety of RNA binding proteins (RBPs), lncRNAs are known to participate in the regulation of RNA splicing and stability [64]. For instance, the RNA binding protein ELAVL1 (embryonic lethal abnormal vision-like protein 1), also known as $\mathrm{HuR}$ (Hu antigen R), is crucial for the nuclear import and stabilization of numerous RNA transcripts [65]. In OSCC, the oncogenic lncRNA SNHG3 (small nucleolar RNA host gene 3) was reported to be localized in the cytoplasm and capable of recruiting ELAVL1, and thereby stabilizing NFYC (transcription factor Y subunit gamma) mRNA to upregulate the expression of NFYC, which in turn promotes cell proliferation and migration [66] (Figure 1e).

Collectively, through interplay with different types of bio-molecules, oral cancerassociated lncRNAs engage in a variety of critical steps in oral carcinogenesis. These findings substantiate the potential of these lncRNAs as key regulators of oral tumorigenesis. Of note, several other kinds of functional mechanism of lncRNAs have not yet been reported in oral cancer. For example, a few lncRNAs harboring small open reading frames (sORFs) could be translated into micro-peptides (usually fewer than 100 amino acids), whereas some tumor-related functional peptides are reported to regulate biological processes and influence tumorigenesis and progression steps [67,68]. In addition, another class of lncRNAs are responsible for alternative splicing during tumorigenesis, through regulating the phosphorylation status or hijacking splicing factors [47]. With the variety of novel mechanisms described above, additional mechanistic scenarios adapted by lncRNAs in oral cancer are expected to be unraveled in the near future. 
Table 1. LncRNAs in oral cancer.

\begin{tabular}{|c|c|c|c|c|c|c|c|}
\hline lncRNA & $\begin{array}{l}\text { Expression Levels } \\
\text { in Cancer }\end{array}$ & Clinical Association & $\begin{array}{l}\text { Functional } \\
\text { Regulation }\end{array}$ & Interactor & Target/Effect & Mechanistic Classification & Refs \\
\hline AC007271.3 * & Upregulated & $\begin{array}{l}\text { Expressed in serum and tissues } \\
\text { of OSCC patients } \\
\text { Associated with clinical stage, } \\
\text { lymph node metastasis (LNM), } \\
\text { poor histological differentiation, } \\
\text { and unfavorable prognosis }\end{array}$ & $\begin{array}{l}\uparrow \text { Proliferation } \\
\uparrow \text { Migration } \\
\uparrow \text { Invasion } \\
\downarrow \text { Apoptosis }\end{array}$ & N.D. & $\begin{array}{l}\beta \text {-catenin and its } \\
\text { downstream target } \\
\text { molecules CyclinD1, } \\
\text { c-myc and Bcl-2 }\end{array}$ & Unclear mechanism & {$[69,70]$} \\
\hline \multirow{3}{*}{$A N R I L^{*}$} & \multirow{3}{*}{ Upregulated } & \multirow{3}{*}{$\begin{array}{l}\text { Expressed in serum and tissues } \\
\text { of OSCC patients } \\
\text { Overexpressed during } \\
\text { carcinogenesis and correlated } \\
\text { with both high TNM stage and } \\
\text { lymph node metastasis (LNM) }\end{array}$} & \multirow{3}{*}{$\begin{array}{l}\uparrow \text { Proliferation } \\
\uparrow \text { Migration } \\
\uparrow \text { Invasion } \\
\downarrow \text { Apoptosis } \\
\downarrow \text { Cisplatin } \\
\text { cytotoxicity }\end{array}$} & $\operatorname{miR}-125 a$ & $\begin{array}{c}\text { Estrogen Related } \\
\text { Receptor } \alpha \text { (ESRRA) }\end{array}$ & $\begin{array}{c}\text { Sequestration of } \\
\text { miRNAs } \\
\text { (ANRIL acts as a miR-125a } \\
\text { sponge, thereby enhancing } \\
\text { ESRRA expression) }\end{array}$ & [56] \\
\hline & & & & N.D. & $\begin{array}{c}\text { TGF- } \beta \text { /Smad signaling } \\
\text { pathway }\end{array}$ & Unclear mechanism & [71] \\
\hline & & & & N.D. & $\begin{array}{c}\text { Drug transporters (MRP1 } \\
\text { and ABCC2) }\end{array}$ & Unclear mechanism & [72] \\
\hline$B C 200$ & Upregulated & N.D. & $\begin{array}{l}\uparrow \text { Proliferation } \\
\uparrow \text { Migration }\end{array}$ & N.D. & $\begin{array}{l}\text { MMP-9 and MMP-13 } \\
\text { expression }\end{array}$ & Unclear mechanism & [73] \\
\hline BLACAT1 & Upregulated & N.D. & $\begin{array}{l}\uparrow \text { Viability } \\
\uparrow \text { Migration } \\
\uparrow \text { Invasion }\end{array}$ & $\operatorname{miR}-142-5 p$ & N.D. & $\begin{array}{l}\text { Sequestration of } \\
\text { miRNAs } \\
\text { (BLACAT1 acts as a } \\
\text { miR-142-5p sponge) }\end{array}$ & [74] \\
\hline C5orf66-AS1 & Downregulated & N.D. & $\begin{array}{l}\downarrow \text { Cell growth } \\
\downarrow \text { Metastasis }\end{array}$ & N.D. & CYC1 expression & Unclear mechanism & [24] \\
\hline \multirow[b]{2}{*}{ CASC2 } & \multirow[b]{2}{*}{ Downregulated } & \multirow{2}{*}{$\begin{array}{l}\text { Correlated with tumor size and } \\
\text { adverse clinicopathological } \\
\text { characteristics of OSCC patients } \\
\text { Expression was increased in } \\
\text { patients without recurrence }\end{array}$} & \multirow[b]{2}{*}{$\begin{array}{l}\downarrow \text { Migration } \\
\downarrow \text { Invasion } \\
\downarrow \text { Proliferation } \\
\uparrow \text { Apoptosis }\end{array}$} & N.D. & $\begin{array}{c}\text { Downregulation of } \\
\text { CDK1 }\end{array}$ & Unclear mechanism & {$[25]$} \\
\hline & & & & miRNA-21 & PDCD4 expression & $\begin{array}{c}\text { Sequestration of miRNAs } \\
\text { (CASC } 2 \text { acts as a miRNA-21 } \\
\text { sponge, thereby enhancing } \\
\text { PDCD } 4 \text { expression) }\end{array}$ & [27] \\
\hline
\end{tabular}


Table 1. Cont.

\begin{tabular}{|c|c|c|c|c|c|c|c|}
\hline $\operatorname{lncRNA}$ & $\begin{array}{c}\text { Expression Levels } \\
\text { in Cancer }\end{array}$ & Clinical Association & Functional Regulation & Interactor & Target/Effect & $\begin{array}{c}\text { Mechanistic } \\
\text { Classification }\end{array}$ & Refs \\
\hline CASC $9 *$ & Upregulated & $\begin{array}{l}\text { Associated with tumor size, } \\
\text { clinical stage, regional lymph } \\
\text { node metastasis, and overall } \\
\text { survival time in OSCC } \\
\text { patients }\end{array}$ & $\begin{array}{c}\uparrow \text { Proliferation } \\
\downarrow \text { Autophagy-mediated } \\
\text { cell apoptosis }\end{array}$ & N.D. & AKT/mTOR pathway & Unclear mechanism & {$[75]$} \\
\hline CASC15 & Upregulated & $\begin{array}{l}\text { - Expressed in plasma of stage } \\
\text { I and II OSCC patients } \\
\text { Inversely correlated with } \\
\text { IncRNA MEG3 in OSCC } \\
\text { tissues }\end{array}$ & $\uparrow$ Proliferation & N.D. & MEG3 & Unclear mechanism & [76] \\
\hline \multirow[b]{2}{*}{$C C A T 1^{*}$} & \multirow[b]{2}{*}{ Upregulated } & \multirow[b]{2}{*}{ N.D. } & \multirow[b]{2}{*}{$\begin{array}{l}\uparrow \text { Proliferation } \\
\uparrow \text { Migration } \\
\uparrow \text { Invasion } \\
\downarrow \text { Apoptosis }\end{array}$} & miR-181a & Wnt/ $\beta$-catenin signaling & \multirow[b]{2}{*}{$\begin{array}{l}\text { Sequestration of miRNAs } \\
\text { (CCAT1 acts as a miRNA } \\
\text { sponge) }\end{array}$} & \multirow[b]{2}{*}[77,78]{} \\
\hline & & & & $\begin{array}{l}\text { miR155-5p and } \\
\text { let7b-5p }\end{array}$ & N.D. & & \\
\hline CCHE1 & Upregulated & N.D. & $\begin{array}{l}\uparrow \text { Proliferation } \\
\uparrow \text { Migration } \\
\uparrow \text { Invasion } \\
\downarrow \text { Apoptosis }\end{array}$ & miR-922 & PAK2 expression & $\begin{array}{l}\text { Sequestration of miRNAs } \\
\text { (CCHE1 acts as a } \\
\text { miR-922sponge, thereby } \\
\text { enhancing PAK2 } \\
\text { expression) }\end{array}$ & [79] \\
\hline CEBPA-AS1* & Upregulated & $\begin{array}{l}\text { Correlated with poor } \\
\text { differentiation, lymph node } \\
\text { metastasis, and high clinical } \\
\text { stage }\end{array}$ & $\begin{array}{l}\uparrow \text { Proliferation } \\
\uparrow \text { Migration } \\
\uparrow \text { Invasion } \\
\downarrow \text { Apoptosis }\end{array}$ & CEBPA & Bcl-2 expression & $\begin{array}{c}\text { Post-transcriptional } \\
\text { regulation } \\
(C E B P A-A S 1 \text { might form a } \\
\text { "lncRNA-mRNA" pair } \\
\text { with CEBPA and regulate } \\
\text { CEBPA expression in a cis } \\
\text { manner) }\end{array}$ & [48] \\
\hline CRNDE & Upregulated & N.D. & $\begin{array}{l}\uparrow \text { Proliferation } \\
\uparrow \text { Migration } \\
\uparrow \text { Invasion } \\
\uparrow \text { EMT } \\
\downarrow \text { Apoptosis }\end{array}$ & N.D. & Wnt/ $\beta$-catenin signaling & Unclear mechanism & [80] \\
\hline
\end{tabular}


Table 1. Cont.

\begin{tabular}{|c|c|c|c|c|c|c|c|}
\hline $\operatorname{lncRNA}$ & $\begin{array}{c}\text { Expression Levels } \\
\text { in Cancer }\end{array}$ & Clinical Association & Functional Regulation & Interactor & Target/Effect & $\begin{array}{c}\text { Mechanistic } \\
\text { Classification }\end{array}$ & Refs \\
\hline DANCR & Upregulated & $\begin{array}{l}\text { Correlated with higher } \\
\text { clinical stage, lower } \\
\text { differentiation degree, or } \\
\text { lymph node metastasis }\end{array}$ & $\begin{array}{l}\uparrow \text { Proliferation } \\
\uparrow \text { Migration } \\
\uparrow \text { Invasion } \\
\downarrow \text { Apoptosis }\end{array}$ & $\operatorname{miR}-216 a-5 p$ & $\begin{array}{l}\text { Bcl-2 expression } \\
\text { KLF12 expression }\end{array}$ & $\begin{array}{l}\text { Sequestration of miRNAs } \\
\text { (DANCR acts as a } \\
\text { miR-216a-5p sponge, } \\
\text { thereby enhancing Bcl-2 } \\
\text { and KLF12 expression) }\end{array}$ & [81] \\
\hline DNM3OS & Upregulated & N.D. & $\begin{array}{c}\uparrow \text { Viability } \\
\uparrow \text { Migration }\end{array}$ & miR-204-5p & HIP1 expression & $\begin{array}{l}\text { Sequestration of miRNAs } \\
\text { (DNM3OS acts as a } \\
\text { miR-204-5p sponge, } \\
\text { thereby enhancing HIP1 } \\
\text { expression) }\end{array}$ & [82] \\
\hline ELF3-AS1 & Upregulated & N.D. & $\uparrow$ Proliferation & N.D. & GLUT1 expression & Unclear mechanism & [83] \\
\hline ENST00000470447.1 & Downregulated & $\begin{array}{l}\text { - Correlated with tumor } \\
\text { differentiation } \\
\text { High expression was } \\
\text { associated with better } \\
\text { disease-free survival for } \\
\text { patients }\end{array}$ & $\begin{array}{l}\downarrow \text { Proliferation } \\
\downarrow \downarrow \text { Migration } \\
\downarrow \downarrow \text { Invasion } \\
\uparrow \text { Apoptosis }\end{array}$ & N.D. & N.D. & Unclear mechanism & [28] \\
\hline FAL1 & Upregulated & N.D. & $\uparrow$ Proliferation & $\operatorname{miR}-761$ & CRKL expression & $\begin{array}{l}\text { Sequestration of miRNAs } \\
\text { (FAL1 acts as a miR-761 } \\
\text { sponge, thereby enhancing } \\
\text { CRKL expression) }\end{array}$ & [84] \\
\hline FALEC * & Downregulated & N.D. & $\begin{array}{l}\downarrow \text { Proliferation } \\
\downarrow \text { Migration }\end{array}$ & $\mathrm{EZH} 2$ & ECM1 expression & $\begin{array}{c}\text { Epigenetic and } \\
\text { transcriptional regulation } \\
(F A L E C \text { inhibited } \\
\text { transcription through } \\
\text { recruiting EZH2 to the } \\
\text { promoter of ECM1) }\end{array}$ & [29] \\
\hline
\end{tabular}


Table 1. Cont.

\begin{tabular}{|c|c|c|c|c|c|c|c|}
\hline lncRNA & $\begin{array}{c}\text { Expression Levels } \\
\text { in Cancer }\end{array}$ & Clinical Association & Functional Regulation & Interactor & Target/Effect & $\begin{array}{c}\text { Mechanistic } \\
\text { Classification }\end{array}$ & Refs \\
\hline \multirow{2}{*}{ FGD5-AS1 * } & \multirow{2}{*}{ Upregulated } & \multirow{2}{*}{ N.D. } & \multirow{2}{*}{$\begin{array}{l}\uparrow \text { Proliferation } \\
\uparrow \text { Migration } \\
\uparrow \text { Invasion } \\
\downarrow \text { Apoptosis }\end{array}$} & miR-153-3p & MCL1 expression & \multirow{2}{*}{$\begin{array}{l}\text { Sequestration of miRNAs } \\
\text { (FGD5- } A S 1 \text { acts as a } \\
\text { miRNA sponge, thereby } \\
\text { enhancing the expression } \\
\text { of their targets) }\end{array}$} & \multirow{2}{*}[57,85]{} \\
\hline & & & & miR-520b & USP21 expression & & \\
\hline GAS5 * & Downregulated & N.D. & $\begin{array}{c}\downarrow \text { Proliferation } \\
\downarrow \text { Migration } \\
\downarrow \text { Invasion } \\
\quad \downarrow \text { EMT }\end{array}$ & miR-21 & $\begin{array}{l}\text { Regulation of PI3K/Akt } \\
\text { pathwayPTEN } \\
\text { expression }\end{array}$ & $\begin{array}{l}\text { Sequestration of miRNAs } \\
\text { (GAS5 acts as a miR-21 } \\
\text { sponge, thereby enhancing } \\
\text { PTEN expression) }\end{array}$ & {$[86,87]$} \\
\hline$H 19$ * & Upregulated & $\begin{array}{l}\text { - Associated with the TNM } \\
\text { stage, nodal invasion, and } \\
\text { shorter overall survival of } \\
\text { patients }\end{array}$ & $\begin{array}{l}\uparrow \text { Proliferation } \\
\uparrow \text { Migration } \\
\uparrow \text { Invasion } \\
\uparrow \text { EMT } \\
\downarrow \text { Apoptosis }\end{array}$ & miR-138 & EZH2 expression & $\begin{array}{l}\text { Sequestration of miRNAs } \\
\text { (H19 acts as a miR-138 } \\
\text { sponge, thereby enhancing } \\
\text { EZH2 expression) }\end{array}$ & [58] \\
\hline HAS2-AS1 * & Upregulated & $\begin{array}{l}\text { - Associated with lymph } \\
\text { node metastasis and } \\
\text { hypoxic tumor status in } \\
\text { patients }\end{array}$ & $\begin{array}{l}\uparrow \text { Invasion } \\
\uparrow \text { EMT }\end{array}$ & HAS2 gene & Transcription of HAS2 & $\begin{array}{c}\text { Transcriptional } \\
\text { regulation } \\
\text { (HAS2-AS1 is necessary for } \\
\text { the transcription of its } \\
\text { sense counterpart } H A S 2 \\
\text { upon hypoxia treatment) }\end{array}$ & [41] \\
\hline HCP5 & Upregulated & $\begin{array}{l}\text { - Associated with the } \\
\text { aggressive } \\
\text { clinicopathological } \\
\text { characteristics and poor } \\
\text { prognosis of patients }\end{array}$ & $\begin{array}{l}\uparrow \text { Proliferation } \\
\uparrow \text { Migration } \\
\uparrow \text { Invasion } \\
\uparrow \text { EMT }\end{array}$ & miR-140-5p & SOX4 expression & $\begin{array}{l}\text { Sequestration of miRNAs } \\
\text { (HCP5 acts as a miR-140-5p } \\
\text { sponge, thereby enhancing } \\
\text { SOX4 expression) }\end{array}$ & [88] \\
\hline
\end{tabular}


Table 1. Cont.

\begin{tabular}{|c|c|c|c|c|c|c|c|}
\hline lncRNA & $\begin{array}{l}\text { Expression Levels } \\
\text { in Cancer }\end{array}$ & Clinical Association & Functional Regulation & Interactor & Target/Effect & $\begin{array}{l}\text { Mechanistic } \\
\text { Classification }\end{array}$ & Refs \\
\hline \multirow[t]{2}{*}{$\begin{array}{l}\text { HIFCAR/ } \\
\text { MIR31HG * }\end{array}$} & \multirow[t]{2}{*}{ Upregulated } & \multirow[t]{2}{*}{$\begin{array}{l}\text { Associated with age and } \\
\text { advanced tumor grade }\end{array}$} & \multirow[t]{2}{*}{$\begin{array}{l}\uparrow \text { Tumor progression } \\
\uparrow \text { Metastatic potential }\end{array}$} & \multirow[t]{2}{*}{ HIF- $1 \alpha$} & HIF- $1 \alpha$ signaling & $\begin{array}{c}\text { Transcriptional } \\
\text { regulation } \\
(L n c H I F C A R \text { acts as } \\
\text { HIF- } 1 \alpha \text { coactivator })\end{array}$ & [43] \\
\hline & & & & & p21 & Unclear mechanism & [44] \\
\hline$H N F 1 A-A S 1$ * & Upregulated & $\begin{array}{l}\text { High expression predicted } \\
\text { poor prognosis for patients }\end{array}$ & $\begin{array}{l}\uparrow \text { Migration } \\
\uparrow \text { Invasion } \\
\uparrow \text { EMT }\end{array}$ & N.D. & $\begin{array}{l}\text { Notch1 and Hes1 } \\
\text { expression }\end{array}$ & Unclear mechanism & [89] \\
\hline \multirow[t]{3}{*}{ HOTAIR * } & \multirow[t]{3}{*}{ Upregulated } & \multirow{3}{*}{$\begin{array}{l}\text { Correlated with TNM } \\
\text { stage, histological grade, } \\
\text { and differentiation, as well } \\
\text { as regional lymph node } \\
\text { metastasis } \\
\text { Overexpression indicated } \\
\text { poor overall survival and } \\
\text { disease-free survival }\end{array}$} & \multirow{3}{*}{$\begin{array}{l}\uparrow \text { Proliferation } \\
\uparrow \text { Migration } \\
\uparrow \text { Invasion } \\
\uparrow \text { EMT } \\
\downarrow \text { Apoptosis } \\
\uparrow \text { Autophagy }\end{array}$} & $\begin{array}{l}\text { EZH2 and } \\
\text { H3K27me3 }\end{array}$ & Regulation of E-cadherin & $\begin{array}{c}\text { Epigenetic and } \\
\text { transcriptional regulation } \\
\text { (HOTAIR regulated } \\
\text { E-cadherin expression } \\
\text { through partly associating } \\
\text { with EZH2 and mediating } \\
\text { H3K27me3 at the promoter } \\
\text { of E-cadherin) }\end{array}$ & [32] \\
\hline & & & & $\operatorname{miR}-326$ & MTA2 expression & $\begin{array}{c}\text { Sequestration of miRNAs } \\
\text { (HOTAIR acts as a miR-326 } \\
\text { sponge, thereby enhancing } \\
\text { MTA2 expression) }\end{array}$ & [37] \\
\hline & & & & N.D. & $\begin{array}{c}\text { Regulation of mTOR and } \\
\text { the autophagy-related } \\
\text { factors }\end{array}$ & Unclear mechanism & [36] \\
\hline \multirow[t]{2}{*}{ HOTTIP } & \multirow[t]{2}{*}{ Upregulated } & \multirow{2}{*}{$\begin{array}{l}\text { Associated with lymph } \\
\text { node metastasis and } \\
\text { late-stage OTSCC patients } \\
\text { - Correlated with poor } \\
\text { prognosis }\end{array}$} & \multirow{2}{*}{$\begin{array}{l}\uparrow \text { Proliferation } \\
\uparrow \text { Migration } \\
\uparrow \text { Invasion } \\
\uparrow \text { EMT } \\
\downarrow \text { Apoptosis }\end{array}$} & miR-124-3p & $\begin{array}{l}\text { HMGA2 } \\
\text { expressionWnt/ } \beta- \\
\text { catenin } \\
\text { pathway }\end{array}$ & $\begin{array}{c}\text { Sequestration of miRNAs } \\
\text { (HOTTIP acts as a } \\
\text { miR-124-3p sponge, } \\
\text { thereby enhancing } \\
\text { HMGA2 expression) }\end{array}$ & [90] \\
\hline & & & & N.D. & $\begin{array}{c}\text { Cell cycle arrest at G1 } \\
\text { phase }\end{array}$ & Unclear mechanism & [91] \\
\hline
\end{tabular}


Table 1. Cont.

\begin{tabular}{|c|c|c|c|c|c|c|c|}
\hline $\operatorname{lncRNA}$ & $\begin{array}{c}\text { Expression Levels } \\
\text { in Cancer }\end{array}$ & Clinical Association & Functional Regulation & Interactor & Target/Effect & $\begin{array}{c}\text { Mechanistic } \\
\text { Classification }\end{array}$ & Refs \\
\hline \multirow{3}{*}{ HOXA11-AS } & \multirow{3}{*}{ Upregulated } & \multirow{3}{*}{ N.D. } & \multirow{3}{*}{$\begin{array}{c}\uparrow \text { Proliferation } \\
\uparrow \text { Migration } \\
\uparrow \text { Invasion } \\
\uparrow \text { EMT } \\
\downarrow \text { Apoptosis } \\
\downarrow \text { CDDP cytotoxicity }\end{array}$} & miR-98-5p & YBX2 expression & \multirow{3}{*}{$\begin{array}{l}\text { Sequestration of miRNAs } \\
\text { (HOXA11-AS acts as a } \\
\text { miRNA sponge, thereby } \\
\text { enhancing the expression } \\
\text { of their targets) }\end{array}$} & \multirow{3}{*}[92-94]{} \\
\hline & & & & miR-518a-3p & PDK1 expression & & \\
\hline & & & & miR-214-3p & PIM1 expression & & \\
\hline HOXC13-AS & Upregulated & N.D. & $\begin{array}{l}\uparrow \text { Proliferation } \\
\uparrow \text { Migration } \\
\uparrow \text { EMT }\end{array}$ & $\operatorname{miR}-378 \mathrm{~g}$ & HOXC13 expression & $\begin{array}{l}\text { Sequestration of miRNAs } \\
\text { (HOXC13- } A S \text { acts as a } \\
\text { miR-378g sponge, thereby } \\
\text { enhancing HOXC13 } \\
\text { expression) }\end{array}$ & [95] \\
\hline HULC & Upregulated & N.D. & $\begin{array}{c}\uparrow \text { Proliferation } \\
\uparrow \text { Migration } \\
\uparrow \text { Invasion } \\
\downarrow \text { Apoptosis } \\
\uparrow \text { EMT } \\
\uparrow \text { CDDP tolerance }\end{array}$ & N.D. & N.D. & Unclear mechanism & [96] \\
\hline$J P X$ & Upregulated & N.D. & $\begin{array}{l}\uparrow \text { Proliferation } \\
\uparrow \text { Migration } \\
\uparrow \text { Invasion }\end{array}$ & miR-944 & $\mathrm{CDH} 2$ expression & $\begin{array}{c}\text { Sequestration of miRNAs } \\
\text { (JPX acts as a } \\
\text { miR-944sponge, thereby } \\
\text { enhancing CDH2 } \\
\text { expression) }\end{array}$ & [97] \\
\hline LEF1-AS1 * & Upregulated & $\begin{array}{l}\text { - Relevant to poor prognosis } \\
\text { in OSCC }\end{array}$ & $\begin{array}{c}\uparrow \text { Survival and } \\
\text { proliferation } \\
\uparrow \text { Migration } \\
\uparrow \text { Invasion } \\
\downarrow \text { Apoptosis }\end{array}$ & LATS1 & $\begin{array}{l}\text { Regulation of Hippo } \\
\text { signaling }\end{array}$ & $\begin{array}{c}\text { Interaction Decoy } \\
\text { (LEF1-AS1 can interact } \\
\text { with LATS1 and therefore } \\
\text { regulates Hippo signaling) }\end{array}$ & [98] \\
\hline LINC00152 & Upregulated & $\begin{array}{l}\text { - Associated with decreased } \\
\text { survival in patients }\end{array}$ & $\begin{array}{c}\uparrow \text { Proliferation } \\
\uparrow \text { Colony formation } \\
\uparrow \text { Migration } \\
\uparrow \text { Invasion } \\
\uparrow \text { EMT }\end{array}$ & miR-139-5p & N.C. & $\begin{array}{l}\text { Sequestration of miRNAs } \\
\text { (LINC00152 acts as a } \\
\text { miR-139-5p sponge) }\end{array}$ & [99] \\
\hline
\end{tabular}


Table 1. Cont.

\begin{tabular}{|c|c|c|c|c|c|c|c|}
\hline $\operatorname{lncRNA}$ & $\begin{array}{l}\text { Expression Levels } \\
\text { in Cancer }\end{array}$ & Clinical Association & Functional Regulation & Interactor & Target/Effect & $\begin{array}{l}\text { Mechanistic } \\
\text { Classification }\end{array}$ & Refs \\
\hline LINC00319 & Upregulated & N.D. & $\begin{array}{c}\uparrow \text { Proliferation } \\
\uparrow \text { Metastasis } \\
\uparrow \text { EMT } \\
\uparrow \text { Angiogenesis } \\
\end{array}$ & miR-199a-5p & FZD4 expression & $\begin{array}{c}\text { Sequestration of miRNAs } \\
\text { (LINC00319 acts as a } \\
\text { miR-199a-5p sponge, } \\
\text { thereby enhancing FZD4 } \\
\text { expression) }\end{array}$ & [100] \\
\hline LINC00941* & Upregulated & N.D. & $\begin{array}{c}\uparrow \text { Proliferation } \\
\uparrow \text { Colony formation }\end{array}$ & CAPRIN2 & $\begin{array}{l}\text { CAPRIN2 expression } \\
\text { Canonical } \\
\text { WNT } / \beta \text {-catenin } \\
\text { signaling }\end{array}$ & $\begin{array}{c}\text { Transcriptional } \\
\text { regulation } \\
\text { (LINC00941 acts as } \\
\text { transcriptional activator by } \\
\text { looping to CAPRIN2 } \\
\text { promoter) }\end{array}$ & [39] \\
\hline LINC00958 & Upregulated & $\begin{array}{l}\text { - Associated with poor } \\
\text { prognosis }\end{array}$ & $\begin{array}{l}\uparrow \text { Proliferation } \\
\uparrow \text { Invasion } \\
\downarrow \text { Apoptosis }\end{array}$ & miR-185-5p & YWHAZ expression & $\begin{array}{l}\text { Sequestration of miRNAs } \\
\text { (LINC00958 acts as a } \\
\text { miR-185-5p sponge, } \\
\text { thereby enhancing } \\
\text { YWHAZ expression) }\end{array}$ & [101] \\
\hline LINC01315 * & Downregulated & N.D. & $\begin{array}{l}\downarrow \text { Proliferation } \\
\downarrow \text { Migration } \\
\downarrow \text { Invasion } \\
\uparrow \text { Apoptosis }\end{array}$ & $\operatorname{miR}-211$ & $\begin{array}{c}\text { DLG3 expression } \\
\text { Regulation of Hippo } \\
\text { signaling pathway }\end{array}$ & $\begin{array}{l}\text { Sequestration of miRNAs } \\
\text { (LINC01315 acts as a } \\
\text { miR-211 sponge, thereby } \\
\text { enhancing DLG3 } \\
\text { expression) }\end{array}$ & {$[30]$} \\
\hline$\underset{*}{\operatorname{LncRNA-p23154}}$ & Upregulated & N.D. & $\begin{array}{l}\uparrow \text { Metastasis } \\
\uparrow \text { Glycolysis }\end{array}$ & $\begin{array}{l}\text { Promoter } \\
\text { region of } \\
\text { miR-378a-3p }\end{array}$ & GLUT1 expression & $\begin{array}{c}\text { Transcriptional } \\
\text { regulation } \\
(L n c R N A-p 23154 \text { binds to } \\
\text { the promoter region of } \\
\text { miR-378a-3p) }\end{array}$ & [40] \\
\hline LUCAT1 & Upregulated & - $\quad$ Associated with tumor size & $\begin{array}{l}\uparrow \text { Cell growth } \\
\uparrow \text { Proliferation }\end{array}$ & N.D. & MAPK signaling & Unclear mechanism & [103] \\
\hline
\end{tabular}


Table 1. Cont.

\begin{tabular}{|c|c|c|c|c|c|c|c|}
\hline $\operatorname{lncRNA}$ & $\begin{array}{c}\text { Expression Levels } \\
\text { in Cancer }\end{array}$ & Clinical Association & Functional Regulation & Interactor & Target/Effect & Mechanistic Classification & Refs \\
\hline \multirow{6}{*}{ MALAT1 * } & \multirow{6}{*}{ Upregulated } & \multirow{6}{*}{$\begin{array}{ll}\text { - } & \text { Promotes OSCC } \\
\text { progression }\end{array}$} & \multirow{6}{*}{$\begin{array}{c}\uparrow \text { Proliferation } \\
\uparrow \text { Migration } \\
\uparrow \text { Invasion } \\
\uparrow \text { EMT } \\
\downarrow \text { Apoptosis } \\
\downarrow \text { DDP-resistance }\end{array}$} & miR-143-3p & MAGEA9 expression & \multirow{4}{*}{$\begin{array}{c}\text { Sequestration of miRNAs } \\
\text { (MALAT1 acts as a miRNA } \\
\text { sponge, thereby enhancing } \\
\text { the expression of their } \\
\text { targets) }\end{array}$} & \multirow{4}{*}{$\begin{array}{c}{[59,104-} \\
106]\end{array}$} \\
\hline & & & & miR-140-5p & PAK1 expression & & \\
\hline & & & & $\mathrm{miR}-125 \mathrm{~b}$ & STAT3 expression & & \\
\hline & & & & miR-101 & EZH2 expression & & \\
\hline & & & & N.D. & $\begin{array}{c}\text { P-glycoprotein } \\
\text { expression } \\
\text { PI3K/AKT/m-TOR } \\
\text { signaling }\end{array}$ & \multirow[t]{2}{*}{ Unclear mechanism } & \multirow[t]{2}{*}[107,108]{} \\
\hline & & & & N.D. & Wnt $/ \beta$-catenin signaling & & \\
\hline \multirow{2}{*}{ MCM3AP-AS1 } & \multirow{2}{*}{ Upregulated } & \multirow{2}{*}{$\begin{array}{l}\text { Associated with poor } \\
\text { prognosis in OSCC patients }\end{array}$} & \multirow{2}{*}{$\begin{array}{l}\uparrow \text { Proliferation } \\
\uparrow \text { Migration } \\
\uparrow \text { Invasion }\end{array}$} & miR-204-5p & FOXC1 expression & \multirow{2}{*}{$\begin{array}{c}\text { Sequestration of miRNAs } \\
(M C M 3 A P-A S 1 \text { acts as a } \\
\text { miRNA sponge, thereby } \\
\text { enhancing the expression of } \\
\text { their targets) }\end{array}$} & \multirow{2}{*}[109,110]{} \\
\hline & & & & miR-363-5p & N.D. & & \\
\hline \multirow{4}{*}{$M E G 3$ * } & \multirow{4}{*}{ Downregulated } & \multirow{4}{*}{ N.D. } & \multirow{4}{*}{$\begin{array}{l}\downarrow \text { Proliferation } \\
\downarrow \text { Migration } \\
\quad \downarrow \text { Invasion } \\
\uparrow \text { Apoptosis }\end{array}$} & miR-548d-3p & $\begin{array}{c}\text { SOCS5 and SOCS6 } \\
\text { expression } \\
\text { Regulation of JAK-STAT } \\
\text { signaling }\end{array}$ & \multirow{3}{*}{$\begin{array}{c}\text { Sequestration of miRNAs } \\
\text { (MEG3 acts as a miRNA } \\
\text { sponge, thereby enhancing } \\
\text { the expression of their } \\
\text { targets) }\end{array}$} & \multirow{3}{*}{$\begin{array}{c}{[55,111,} \\
112]\end{array}$} \\
\hline & & & & miR-21 & N.D. & & \\
\hline & & & & miR-361-5p & $\begin{array}{l}\text { Regulation of succinate } \\
\text { dehydrogenase (SDH) }\end{array}$ & & \\
\hline & & & & N.D. & Wnt/ $\beta$-catenin signaling & Unclear mechanism & [113] \\
\hline MIR4435-2HG & Upregulated & N.D. & $\uparrow \mathrm{EMT}$ & miR-296-5p & $\begin{array}{l}\text { Expression of EMT } \\
\text { markers }\end{array}$ & $\begin{array}{l}\text { Sequestration of miRNAs } \\
\text { (MIR4435-2HG acts as a } \\
\text { miR-296-5p sponge) }\end{array}$ & [114] \\
\hline
\end{tabular}


Table 1. Cont.

\begin{tabular}{|c|c|c|c|c|c|c|c|}
\hline lncRNA & $\begin{array}{l}\text { Expression Levels } \\
\text { in Cancer }\end{array}$ & Clinical Association & Functional Regulation & Interactor & Target/Effect & Mechanistic Classification & Refs \\
\hline MORT & Downregulated & $\begin{array}{l}\text { - Low expression level was } \\
\text { correlated with poor } \\
\text { survival }\end{array}$ & $\downarrow$ Proliferation & N.D. & ROCK1 expression & Unclear mechanism & {$[31]$} \\
\hline MYOSLID & Upregulated & $\begin{array}{l}\text { - Advanced OSCC patients } \\
\text { had higher MYOSLID } \\
\text { expression levels than } \\
\text { those in early stage } \\
\text { patients }\end{array}$ & $\begin{array}{l}\uparrow \text { Migration } \\
\uparrow \text { Invasion }\end{array}$ & N.D. & $\begin{array}{c}\text { Expression of } \\
\text { EMT-related markers }\end{array}$ & Unclear mechanism & [115] \\
\hline NEAT1 & Upregulated & $\begin{array}{l}\text { - Correlated with aggressive } \\
\text { tumor phenotypes and } \\
\text { poor prognosis }\end{array}$ & $\begin{array}{l}\uparrow \text { Proliferation } \\
\uparrow \text { Migration } \\
\uparrow \text { Invasion } \\
\downarrow \text { Apoptosis }\end{array}$ & $\operatorname{miR}-365$ & RGS20 expression & $\begin{array}{l}\text { Sequestration of miRNAs } \\
\text { (NEAT1 acts as a miR-365 } \\
\text { sponge, thereby enhancing } \\
\text { RGS20 expression) }\end{array}$ & [116] \\
\hline \multirow[b]{2}{*}{ OIP5-AS1 } & \multirow[b]{2}{*}{ Upregulated } & \multirow[b]{2}{*}{$\begin{array}{l}\text { Overexpression in oral } \\
\text { tumors with } \\
\text { undifferentiated cellular } \\
\text { pathology } \\
\text { Overexpression is common } \\
\text { in human cancers of } \\
\text { epithelial origin }\end{array}$} & & miR-338-3p & NRP1 expression & \multirow[b]{2}{*}{$\begin{array}{c}\text { Sequestration of miRNAs } \\
\text { (OIP5-AS1 acts as a miRNA } \\
\text { sponge, thereby enhancing } \\
\text { the expression of their } \\
\text { targets) }\end{array}$} & \multirow[b]{2}{*}[117,118]{} \\
\hline & & & $\begin{array}{c}\uparrow \text { Proliferation } \\
\uparrow \\
\text { Migration } \uparrow \text { Invasion }\end{array}$ & $\begin{array}{l}\text { miR-137 } \\
\text { miR148a-3p } \\
\text { miR-30a-5p } \\
\text { miR-30b-5p } \\
\text { miR-338-3p } \\
\text { miR-22-3p }\end{array}$ & N.D. & & \\
\hline PAPAS * & Upregulated & $\begin{array}{l}\text { - Associated with worse } \\
\text { survival conditions }\end{array}$ & $\begin{array}{l}\uparrow \text { Migration } \\
\uparrow \text { Invasion }\end{array}$ & N.D. & TGF- $\beta$ signaling & Unclear mechanism & [119] \\
\hline$P L A C 2$ * & Upregulated & N.D. & $\begin{array}{l}\uparrow \text { Proliferation } \\
\uparrow \text { Invasion }\end{array}$ & N.D. & Wnt/ $\beta$-catenin signaling & Unclear mechanism & [120] \\
\hline
\end{tabular}


Table 1. Cont.

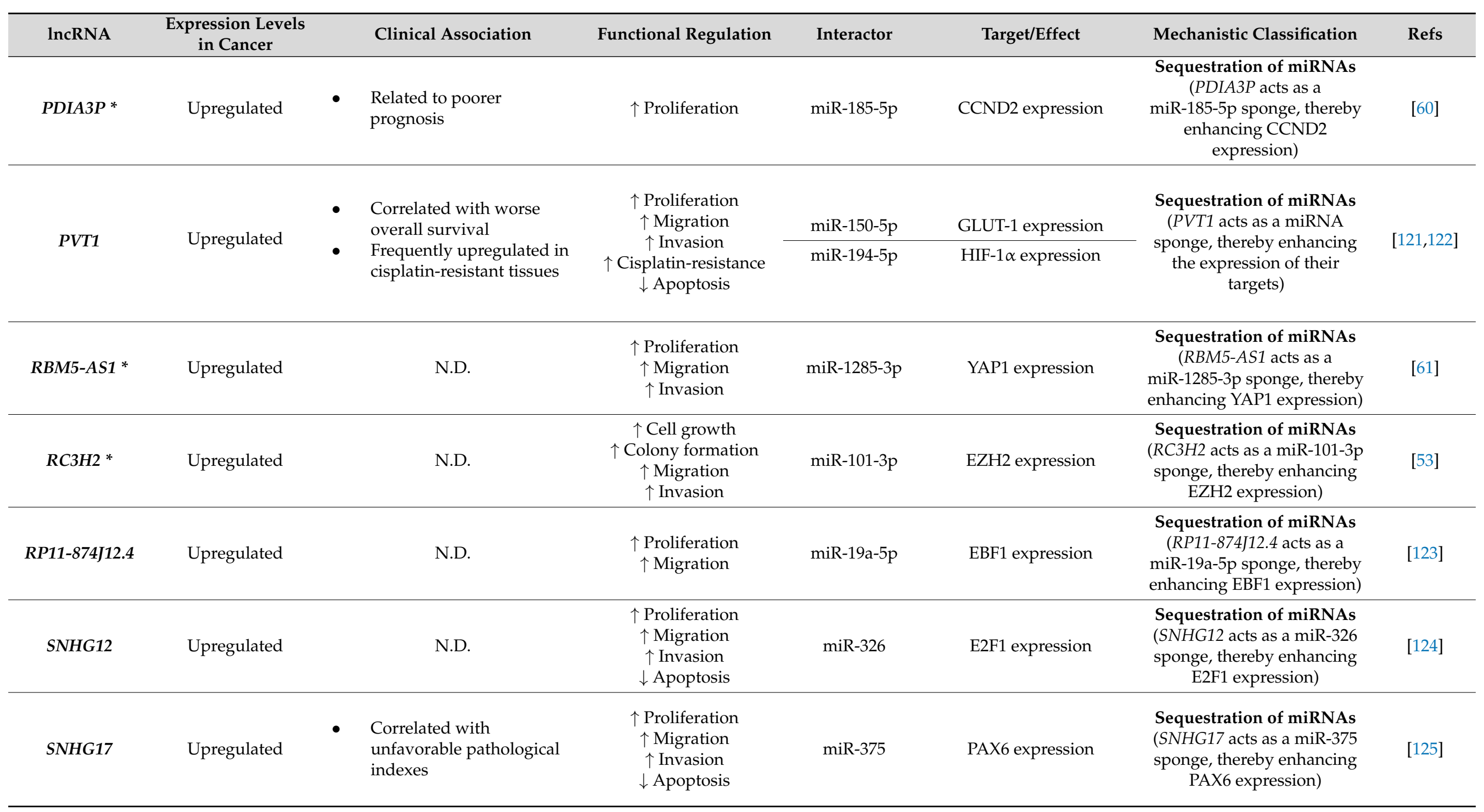


Table 1. Cont.

\begin{tabular}{|c|c|c|c|c|c|c|c|}
\hline $\operatorname{lncRNA}$ & $\begin{array}{c}\text { Expression Levels } \\
\text { in Cancer }\end{array}$ & Clinical Association & Functional Regulation & Interactor & Target/Effect & Mechanistic Classification & Refs \\
\hline \multirow{2}{*}{ SNHG20 * } & \multirow{2}{*}{ Upregulated } & \multirow{2}{*}{$\begin{array}{l}\text { Associated with tumor } \\
\text { differentiation and TNM } \\
\text { stage } \\
\text { Higher expression } \\
\text { predicted a poor overall } \\
\text { survival (OS) rate in } \\
\text { patients }\end{array}$} & \multirow{2}{*}{$\begin{array}{l}\uparrow \text { Proliferation } \\
\uparrow \text { Migration } \\
\uparrow \text { Invasion } \\
\uparrow \text { CSC properties }\end{array}$} & $\operatorname{miR}-29 a$ & $\begin{array}{l}\text { DIXDC1 expression } \\
\text { Regulation of Wnt } \\
\text { signaling }\end{array}$ & \multirow{2}{*}{$\begin{array}{c}\text { Sequestration of miRNAs } \\
\text { (SNHG20 acts as a miRNA } \\
\text { sponge, thereby enhancing } \\
\text { the expression of their } \\
\text { targets) }\end{array}$} & \multirow{2}{*}{$\begin{array}{c}{[54,126} \\
127]\end{array}$} \\
\hline & & & & miR-197 & LIN28 expression & & \\
\hline \multirow{2}{*}{ SNHG3 * } & \multirow{2}{*}{ Upregulated } & \multirow{2}{*}{ N.D. } & \multirow{2}{*}{$\begin{array}{l}\uparrow \text { Proliferation } \\
\uparrow \text { Migration }\end{array}$} & ELAVL1 & $\begin{array}{c}\text { NFYC expression } \\
\text { Wnt/ } \beta \text {-catenin signaling }\end{array}$ & $\begin{array}{c}\text { Protein scaffold } \\
\text { (SNHG3 can bind to ELAVL1 } \\
\text { and therefore stabilize and } \\
\text { upregulate NFYC } \\
\text { expression) }\end{array}$ & [66] \\
\hline & & & & $\operatorname{miR}-2682-5 p$ & HOXB8 expression & $\begin{array}{l}\text { Sequestration of miRNAs } \\
\text { (SNHG3 acts as a } \\
\text { miR-2682-5p sponge, thereby } \\
\text { enhancing HOXB8 } \\
\text { expression) }\end{array}$ & [128] \\
\hline$S O X 21-A S 1$ & Downregulated & $\begin{array}{l}\text { - Correlated with an } \\
\text { advanced stage, large } \\
\text { tumor size, and poor } \\
\text { disease-specific survival }\end{array}$ & $\begin{array}{l}\downarrow \text { Cell growth } \\
\downarrow \downarrow \text { Invasion }\end{array}$ & N.D. & N.D. & Unclear mechanism & [129] \\
\hline TIRY* & Upregulated & $\begin{array}{l}\text { - Higher expression levels in } \\
\text { OSCC tissues predicted } \\
\text { poor prognosis }\end{array}$ & $\begin{array}{l}\uparrow \text { Proliferation } \\
\uparrow \text { Migration } \\
\uparrow \text { Invasion } \\
\uparrow \text { EMT }\end{array}$ & miR-14 & $\begin{array}{c}\text { Expression of EMT } \\
\text { markers } \\
\text { Wnt/ } \beta \text {-catenin signaling }\end{array}$ & Unclear mechanism & [130] \\
\hline
\end{tabular}


Table 1. Cont.

\begin{tabular}{|c|c|c|c|c|c|c|c|}
\hline lncRNA & $\begin{array}{l}\text { Expression Levels } \\
\text { in Cancer }\end{array}$ & Clinical Association & Functional Regulation & Interactor & Target/Effect & Mechanistic Classification & Refs \\
\hline TTN-AS1 * & Upregulated & & $\begin{array}{l}\uparrow \text { Proliferation } \\
\uparrow \text { Migration } \\
\downarrow \text { Apoptosis }\end{array}$ & miR-411-3p & NFAT5 expression & $\begin{array}{c}\text { Sequestration of miRNAs } \\
\text { (TTN-AS1 acts as a } \\
\text { miR-411-3p sponge, thereby } \\
\text { enhancing NFAT5 } \\
\text { expression) }\end{array}$ & [63] \\
\hline \multirow[t]{2}{*}{ TUG1 * } & \multirow[t]{2}{*}{ Upregulated } & \multirow{2}{*}{$\begin{array}{l}\text { - Correlated with TNM } \\
\text { stage, lymph node } \\
\text { metastasis, and tumor } \\
\text { grade in patients }\end{array}$} & \multirow[t]{2}{*}{$\begin{array}{l}\uparrow \text { Proliferation } \\
\uparrow \text { Migration } \\
\uparrow \text { Invasion }\end{array}$} & $\operatorname{miR}-524-5 p$ & DLX1 expression & $\begin{array}{c}\text { Sequestration of miRNAs } \\
\text { (TUG1 acts as a miR-524-5p } \\
\text { sponge, thereby enhancing } \\
\text { DLX1 expression) }\end{array}$ & {$[62]$} \\
\hline & & & & N.D. & Wnt $/ \beta$-catenin signaling & Unclear mechanism & [131] \\
\hline \multirow{3}{*}{ UCA1* } & \multirow{3}{*}{ Upregulated } & \multirow{3}{*}{$\begin{array}{l}\text { Associated with lymph } \\
\text { node metastasis and TNM } \\
\text { stage }\end{array}$} & \multirow{3}{*}{$\begin{array}{c}\uparrow \text { Proliferation } \\
\uparrow \text { Migration } \\
\uparrow \text { Invasion } \\
\uparrow \text { Chemoresistance } \downarrow \\
\text { Apoptosis }\end{array}$} & miR-143-3p & MYO6 expression & \multirow{2}{*}{$\begin{array}{c}\text { Sequestration of miRNAs } \\
\text { (UCA1 acts as a miRNA } \\
\text { sponge, thereby enhancing } \\
\text { the expression of their } \\
\text { targets) }\end{array}$} & \multirow[t]{2}{*}[132,133]{} \\
\hline & & & & miR-184 & SF1 expression & & \\
\hline & & & & N.D. & Wnt/ $\beta$-catenin signaling & Unclear mechanism & {$[134,135]$} \\
\hline
\end{tabular}

* The lncRNAs discussed in the context of this review. 


\section{LncRNAs Involved in Crucial Signaling Pathways}

It is now well appreciated that the genetic alterations in signaling pathways responsible for cell proliferation, cell-cycle progression, and cell death are common hallmarks of cancer. Currently, targeting the oncogenic components in these pathways is a pertinent therapeutic strategy for a variety of tumors, especially for enhancing the chemo-sensitivity and avoiding drug resistance. In oral cancer, a diverse array of pivotal signaling pathways, including the $\mathrm{Wnt} / \beta$-catenin signaling PI3K/AKT/mTOR pathway and others, have been identified as being frequently genetically altered [136]. Emerging evidence has demonstrated that certain IncRNAs could participate in the pathogenesis of oral cancer through these downstream pathways. Here we highlighted the roles of those lncRNAs involved in oncogenic signaling pathways during oral tumorigenesis, which may assist in the discovery of reliable lncRNA-based diagnostics, and preferably, therapeutic strategies for this disease.

\subsection{Wnt/B-Catenin Signaling-Related IncRNAs in Oral Cancer}

Wnt signaling, categorized into canonical $\beta$-catenin-dependent and non-canonical $\beta$-catenin-independent pathways, is an evolutionarily conserved cascade known to be involved in proliferation, regeneration, differentiation, stemness, and development. Recent studies have revealed the emerging prominent oncogenic role of aberrant $\mathrm{Wnt} / \beta$-catenin signaling in OSCC tumorigenesis [137]. In the best studied canonical $\beta$-catenin-dependent pathway, Wnt ligands signal across cell membranes by binding the frizzled receptors and coreceptor LRP (low density lipoprotein receptor-related protein), resulting in the activation of the disheveled proteins (DSH) to phosphorylate LRP5/ 6 (lipoprotein receptor-related proteins $5 / 6$ ), which in turn disassembles the $\beta$-catenin destruction complex containing GSK3 $\beta$ (glycogen synthase kinase- $3 \beta$ ), APC (adenomatous polyposis coli), CK1 (casein kinase 1), and axin (Figure 2a). This leads to stabilization and accumulation of $\beta$-catenin, which subsequently translocates into the nucleus, where nuclear $\beta$-catenin forms a transcriptional complex with the TCF (T-cell factor)/LEF (lymphoid-enhancing factor) family of transcription factors, thereby activating the expression of downstream genes, including $c-M y c, B c l-2$, and Cyclin D1, to promote tumorigenesis (Figure 2) [138].

Currently, several lines of evidence have demonstrated that a series of lncRNAs participate in Wnt $/ \beta$-catenin signaling in oral carcinogenesis. For instance, in TSCC, the aberrant upregulation of lncRNA UCA1 (urothelial carcinoma-associated 1) was found to be associated with metastasis and TNM classification [135]. UCA1 could activate the WNT/ $\beta$-catenin signaling pathway and the expression of its downstream targets, such as Cyclin D1 and MMP-9, by promoting the translocation of $\beta$-catenin into the nucleus, although the underlying mechanism remains unclear. Similarly, lncRNAs AC007271.3 [70], MALAT1 [107], PLAC2 (placenta-specific protein 2) [120], SNHG3 (small nucleolar RNA host gene 3) [66], and TUG1 (taurine upregulated gene 1) [131] have been reported to induce the upregulation of $\beta$-catenin and subsequent activation of the WNT/b-catenin signaling downstream genes in oral cancer (Figure 2a), though the mechanistic details remain to be further investigated.

As mentioned above, recent studies have identified a large number of lncRNAs acting as miRNA sponges to absorb miRNAs, interfering with their regulatory effects on the downstream mRNA targets. Indeed, in OSCC, lncRNA CCAT1 (colon cancer associated transcript 1 ) was found to activate $W n t / \beta$-catenin signaling via its direct interaction with miR-181a, a suppressor of Wnt inhibitory factor-1 (WIF) [139], and therefore driving cell proliferation, migration, and invasion [78]. Most remarkably, another novel lncRNA, TIRY, was found to be highly overexpressed in cancer-associated fibroblasts (CAFs) from OSCC tissues [130]. Nowadays, cancer-associated fibroblasts (CAFs) are considered as one of the most pivotal and abundant components of the tumor microenvironment, contributing to the tumorigenic features of oral cancer [140]. Notably, Jin et al. demonstrated that TIRYoverexpressing CAFs could promote the invasive phenotypes of OSCC cells through CAFsderived exosomes secretion [130]. Subsequent analysis showed that lncRNA TIRY could physically bind to miR-14 and lead to insufficient miR-14 expression in exosomes derived 
from CAFs, whereas WNT3A mRNA was predicted as the target of miR-14. Collectively, these results implied that TIRY overexpression interferes with the production of miR14 in CAF-derived exosomes, which in turn results in the activation of Wnt/ $\beta$-catenin signaling and the enhanced invasion and metastasis of OSCC [130]. This study not only supports the involvement of lncRNAs in Wnt signaling regulation, but also reveals the potential therapeutic value of CAFs. Meanwhile, the aforementioned lncRNA LINC00941 could provoke canonical Wnt signaling via upregulating the expression of Caprin-2 [39], a positive regulator of Wnt signaling, by promoting GSK3-depedent LRP5/6 phosphorylation (Figure 2a), and thereby promoting OSCC progression [141].

\subsection{PI3K/AKT/mTOR Signaling-Related IncRNAs in Oral Cancer}

The phosphoinositide 3-kinase (PI3K)/AKT/mammalian target of rapamycin (mTOR) pathway, a complicated intracellular signaling cascade involved in multiple cellular processes, such as survival, growth, proliferation, autophagy, apoptosis, angiogenesis, and metabolism, is aberrantly hyper-activated in many cancer types, including oral cancer [142]. Upon initiation, various extracellular growth factors and ligands interact with their respective transmembrane receptor tyrosine kinases (RTKs), leading to subsequent phosphorylation of PI3K and producing the secondary messenger, phosphatidylinositol 3,4,5triphosphate $\left(\mathrm{PIP}_{3}\right)$, which in turn activates its downstream effectors, including Akt and mTOR. Notably, AKT activity is a central determinant in the PI3K pathway. PI3K serves as a positive AKT regulator, whereas PTEN (phosphatase and tensin homolog), a tumor suppressor, is a negative PI3K regulator $[143,144]$. During the last decade, more and more lncRNAs have emerged as critical regulators of PI3K/AKT/mTOR signaling in oral tumorigenesis.

Currently, for the treatment of OSCC, cisplatin (DDP) is the first-line chemotherapy agent, whereas acquired DDP resistance greatly diminishes drug efficacy and survival benefit. In DDP-resistant OSCC, Wang et al. reported the increased expression of IncRNA MALAT1. Specifically, by the activation of PI3K/AKT/mTOR signaling pathway, MALAT1 overexpression could lead to DDP resistance, whereas MALAT1 knockdown could effectively re-sensitize OSCC cells to DDP treatment, suggesting an instrumental role of MALAT1 in PI3K/AKT/mTOR signaling-associated DDP resistance development [108]. Furthermore, PI3K/AKT/mTOR signaling is also known as a critical regulatory pathway of autophagy, a highly conserved catabolic process involving the lysosome-mediated degradation of intracytoplasmic components and participating in a variety of cellular biological activities [145]. Autophagy may block or promote tumor survival, depending on the various tumor types and stages. Recently, in OSCC, another lncRNA CASC9 was found to promote cancer progression through suppressing autophagy-mediated cell apoptosis via inducing AKT phosphorylation and the subsequent activation of the AKT/mTOR pathway [75] (Figure $2 \mathrm{~b}$ ). In contrast, the tumor suppressive lncRNA GAS5 (growth-arrest-specific transcript 5) could suppress proliferation, migration, invasion, and epithelial-mesenchymal transition (EMT) in OSCC [86,87]. Mechanically, GAS5 has been reported to act as a miR-21 sponge in ovarian and cervical cancer. In OSCC, Zeng et al. observed that GAS5 most likely also functions in this way. By sequestering miR-21, GAS5 rescues the expression of PTEN, a negative regulator of PI3K signaling, from miR-21-mediated repression, and thereby inhibiting the PI3K/AKT pathway [87] (Figure 2b). Taken together, accumulating reports have revealed the prominent involvement and implications of lncRNAs in regulating cellular proliferation, drug resistance, and apoptosis through targeting the PI3K/AKT/mTOR signaling cascade during oral carcinogenesis.

\subsection{Other Oncogenic Signaling Pathways-Related Lncrnas in Oral Cancer}

In oral cancer, multiple lncRNAs have also been reported to participate in other oncogenic signaling pathways. For example, TGF- $\beta$ is known to be involved in numerous cellular processes, including proliferation, differentiation, apoptosis, homeostasis, epithelial-mesenchymal transition (EMT), and migration. Dysregulation of TGF- $\beta$ sig- 
naling has been implicated in carcinogenesis and could cooperate with other oncogenic cascades to facilitate the development of aggressive tumors [146,147]. Notably, two lncRNAs PAPAS (promoter and pre-rRNA antisense) [119] and ANRIL (antisense non-coding RNA in the INK4 locus) [71] were recently reported to stimulate TGF- $\beta$ signaling, thus promoting tumor progression, although the underlying mechanism remains uncharacterized. Moreover, a positive regulatory effect of the oncogenic, STAT3-induced lncRNA HNF1AAS1 (hepatocyte nuclear factor 1 homeobox A-antisense RNA 1) on Notch signaling was demonstrated to promote OSCC progression [89]. Nevertheless, another tumor suppressive lncRNA, MEG3, could suppress the JAK-STAT (Janus kinases-signal transducer and activator of transcription) pathway via sponging miR-548d-3p that targets SOCS (suppressor of cytokine signaling proteins), SOCS5, and SOCS6, and thereby inhibiting migration and promoting apoptosis in OSCC [112]. Of note, in OSCC, certain lncRNA-protein interactions could interfere with pivotal signal transduction in tumorigenesis and progression. It has been reported that oncogenic lncRNA LEF1-AS1 (lymphoid enhancer-binding factor 1 antisense RNA 1) participated in the Hippo signaling pathway via interacting with large tumor suppressor kinase 1 (LATS1). Once LEF1-AS1 was silenced, the abolition of the interaction between LEF1-AS1 and LATS1 resulted in elevated binding of LATS1 to the other protein partner, monopolar spindle-one-binder $(\mathrm{MOB})$, triggering the phosphorylation of the carcinogenic transcriptional coactivators YAP1 (yes-associated protein 1) and impairing its nuclear translocation, thereby inhibiting cell survival, proliferation, and migration [98].

Collectively, recent advances in molecular characterization have begun to unravel the functional involvement of lncRNAs in the critical signaling pathways in oral tumorigenesis. This knowledge will surely contribute to our improved understanding of OSCC pathogenesis and can be utilized to develop personalized combinatorial therapeutic strategies.

\section{LncRNAs as Potential Biomarkers and Therapeutic Targets for Oral Cancer: Challenges and Potential}

A biomarker, according to the current definition by the Food and Drug Administration (FDA), is any characteristic indicating normal or pathogenic processes, or any response to therapeutic interventions and exposure [148]. With the concept of precision medicine in cancer therapy, the use of disease-specific biomarkers could help to adjust treatments to individual, or subgroups of, patients. Compared with the common cancer biomarkers used in recent clinical applications, such as tumor-associated enzymes and metabolites, increasing evidence suggests that lncRNAs could be promising biomarkers in cancer diagnosis and prognosis, due to their unique RNA properties of easy detection, more tissue-specific expression, and more stable structure $[149,150]$.

Traditionally, in clinical examination, tissue biopsy is employed as an effective and reliable diagnostic and prognostic tool. According to recent reports, an array of lncRNAs have been reported for their potential adaption to the diagnosis and prognosis of oral cancer. Compared with normal tissues, most of the oral cancer-associated lncRNAs reported so far exhibit higher expression levels in tumor tissue, while some of them are downregulated (Table 1), and are considered to be promising potential biomarkers for tissue biopsy. As more and more dysregulated lncRNAs are found to cause, or be linked to, tumor aggressiveness, further characterization of their differential expression levels in different clinical stages, combined with the existing protein-coding biomarkers could facilitate the development of novel markers of tumor aggressiveness. Furthermore, considering their tissue-specific expression patterns and involvement in pivotal oncogenic signaling pathways, lncRNAs could be utilized for specific cancer subtype diagnosis and targeted therapy [20]. Meanwhile, considering the high degree of intratumor heterogeneity in oral cancer, it would be critical to develop quantitative approaches which could detect not only the abundance, but also the heterogeneity and the spatial distribution, of clinically relevant biomarkers inside tumor samples. In particular, recent advances in in situ RNA fluorescence hybridization assays allow detecting single RNA molecules with high specificity [151,152]. In theory, these microscopical analyses could enable the visualization and accurate quantification of clinically relevant lncRNA biomarkers across entire FFPE tissue sections at a single-cell 
resolution, providing a robust approach for measuring the spatial heterogeneity in FFPE tissue specimens.

However, several drawbacks, such as the requirement for operation, discomfort of the patients, along with the risk and complexity of sample collection, make tissue biopsy an impractical option for the monitoring of patient health over time [153]. Instead, liquid biopsies, the minimally invasive sampling from cell-free fluids, such as blood, urine, saliva, cerebrospinal fluid (CSF), sputum, stool, and pleural effusions [154-156] for the subsequent analysis of "tumor circulome", are emerging as a favorable alternative to conventional tissue biopsies [154,157]. The "tumor circulome" is defined as the subset of circulating components derived from tumor tissues that can be utilized as a reservoir of cancer biomarkers in liquid biopsies [158]. These components include tumor-derived proteins, circulating tumor cells (CTCs), extracellular vesicles (EVs), and extracellular RNAs [154,157].

Over the past few years, the growing number of extracellular lncRNAs found in the body fluids of cancer patients has encouraged more and more investigations. Using deep sequencing methods, altered expression of extracellular lncRNAs has been identified in different types of cancers, which could be of potential clinical relevance. Currently, blood, including plasma or serum, is the most widely used biological specimen in liquid biopsy biomarker development. In oral cancer, rapid expanding experimental data and potential biomarkers have been accumulated and reported. In a cohort comprising 80 OSCC patients and 70 healthy control individuals, Shao et al. demonstrated that aberrant $A C 007271.3$ lncRNA expression in OSCC was significantly correlated with clinical stage, especially in early-stage [69]. Of particular note, serum AC007271.3 level could discriminate between OSCC and normal controls with sensitivities of $77.6 \%$ and specificities of $84.5 \%$, whereas the combined detection of serum AC007271.3 with conventional biomarkers, such as SCCA (squamous cell carcinoma antigen) and TSGF (tumor-specific growth factor), could make further differentiation of these two groups [69], uncovering a promising circulating lncRNA biomarker for OSCC, although further validation with a larger cohort is needed. Apart from AC007271.3, serum lncRNA LOC284454 [159] and plasma CACS15 [76] were also reported to be capable of serving as potential diagnostic biomarkers for OSCC.

In oral cancer, considering its direct contact with oral cancer lesions, as well as the convenience, economy, and safety of the sampling, manipulation, and preservation of saliva, saliva is becoming an attractive alternative to tissue and blood testing. Indeed, with the help of novel approaches, including metabolomics, genomics, proteomics, and bioinformatics, the saliva research field is rapidly advancing, with the aim of developing non-invasive salivary biomarkers, such as circulating tumor DNA, extracellular vesicles, miRNAs, and circulating tumor cells, into an effective modality for the early diagnostic detection, prognostic prediction, and continuous post therapy surveillance of this dread malignancy [160]. In the case of salivary lncRNA, Tang et al. investigated the levels of six well-documented cancer-associated lncRNAs in saliva collected from nine OSCC patients. In this pilot report, certain lncRNAs, like HOTAIR and MALAT1, were detectable in their settings and appeared to be potential markers for OSCC diagnosis [161]. However, due to the low abundance of lncRNAs in saliva, specific detection remains a challenge and further improvements should be made before introducing salivary lncRNAs into clinical practice. The conventional analytical Q-PCR methods for salivary analysis, involving many steps, may require further optimization, such as the standardization of sample preparation protocols, endogenous or spike-in controls for normalization of lncRNAs in saliva [162-165], uniform and consistent extraction methods, and differential centrifugation to fractionate saliva samples [166], as well as the increased credibility of qPCR results, with specificity and reliability (our unpublished data), to achieve more specific detection. Moreover, the development of fast, high throughput detection devices, such as biosensor chip technologies, would be critical for salivary lncRNA-based diagnosis and monitoring, and could greatly improve health care outcomes for oral cancer patients. At present, only limited circulating lncRNA biomarkers are approved for informing clinical decision making 
in other types of tumors. Moreover, for the identification of novel lncRNA biomarkers for oral cancer, sufficient clinical cohorts with matched clinical information are urgently needed to validate the performance of these RNA-based biomarkers for early-diagnosis, prognosis, and drug response.

Nevertheless, in the last decade, accumulating GWASs (Genome-wide association study) studies have identified more than 6500 disease-predisposing SNPs, and only 7\% are located in protein-coding regions. Remarkably, structural approaches have revealed that a few SNPs and somatic mutations within lncRNAs could disrupt local RNA structure at functionally relevant sites, affecting their molecular function and expression pattern, revealing that SNPs in cancer-associated lncRNAs may help to categorize patient populations [167]. Indeed, two SNPs within lncRNA H19, rs2839701 and rs217727, were identified related to OSCC susceptibility in a Chinese population [168]. However, to our knowledge, no direct evidence showing that the mutations/SNPs analyzed in OSCC could affect lncRNA secondary and tertiary structures was reported. Currently, the experimental approaches used to decipher RNA structure have been limited to small transcripts or RNA fragments, and unfeasible to scale to genome-wide analyses. Hence, the clinical translation and structural investigation of oral cancer-associated SNPs in GWAS data may warrant future research attention.

Most excitingly, the aforementioned lncRNAs with key roles in oral tumorigenesis could be potential therapeutic targets. Knockdown of multiple specific oncogenic oral cancer-associated lncRNAs has been demonstrated to suppress various aspects of tumor progression and achieve a positive effect (Table 1.), revealing that targeting these transcriptinvolved axes might be new therapeutic option. In light of their sensitivity, tissue-specificity, ease of design, and regulation of specific facets of cellular networks, lncRNAs may be superior to protein with regard to the undesired harmful adverse effects associated with their targeting. Moreover, owing to the lack of translation into proteins, rapid turnover rate, and generally lower expression levels of lncRNAs, targeting lncRNAs suggests fast effects with low doses.

To date, the most advanced and straightforward therapeutic attempts at RNA targeting have been accomplished through direct targeting of sequences via antisense oligonucleotides (ASOs) and siRNA-based therapeutics. Basically, according to sequence homology and RNA accessibility, these oligonucleotide-based molecules can be quickly designed and bind to the target RNA through Watson-Crick base pairing to induce co-transcriptional cleavage or translation repression $[169,170]$. In the past few years, both antisense oligonucleotides (ASOs) and siRNA have received FDA approval for first-of-its-kind mRNAtargeting in Mipomersen $\left(\right.$ Kynamro $\left.^{\mathrm{TM}}\right)$ and patisiran $\left(\mathrm{ONPATTRO}^{\mathrm{TM}}\right)$ for two nonmalignant diseases, familial hypercholesterolemia [171] and transthyretin amyloidosis [172], respectively. Since then, several mRNA-targeting ASOs and siRNAs have been approved, revealing the promise of RNA therapeutics; though neither have yet been proven as an anticancer therapy. Due to in vivo adverse effects and the lack of appropriate delivery systems, there are still limitations to using ASOs and siRNAs in the clinic. A series of chemical modifications and variations have been introduced to improve their pharmacological properties, such as enhancing hybridization affinity to the target RNA, increasing resistance to nuclease-mediated degradation and reducing non-specific immunostimulatory activity $[169,170]$. However, most of the delivery systems and targeting strategies have been applied to mRNAs. On the contrary, the experience with therapeutic lncRNA-targeting is extremely limited. Currently, several ASO- and siRNA-targeting oncogenic lncRNAs are under development and protected by patents. There are both advantages and challenges ahead for IncRNA-targeting therapy. With a deep understanding of lncRNA localization, structures, functional motifs, mechanisms of action, and interplay with other biological molecules, it is believed that lncRNA-based therapy will surely bring disruptive innovation to the field of cancer therapy. 


\section{Conclusions and Perspectives}

Over the past decade, with the advent of various genomic technologies, profiling investigations of lncRNAs in clinical tissue samples have revealed the key role played by lncRNAs in oral tumorigenesis; filling current research gaps in our understanding of cancer biology. This review has presented an updated summary of our current knowledge regarding dysregulated lncRNA profiles and their mechanisms of action in oral cancer (Table 1 and Figure 1), highlighting the functional annotation and regulatory role of these oral cancer-associated lncRNAs in profound oncogenic signaling pathways (Figure 2). Collectively, these recent discoveries in oral cancer have strengthened the idea that long non-coding RNA indeed acts as the molecular functional code to fine tune cellular gene expression. LncRNAs can participate in the development and progression of oral cancer at diverse levels, including epigenetic, transcriptional, and post-transcriptional steps via an elaborate network consisting of various kinds of RNA, chromatin DNA, and protein factors, although the underlying mechanisms of most oral cancer-associated lncRNAs remain largely unknown.

In recent years, for healthcare research, the development of non-invasive approaches to monitoring health states, tumor progression, and post-treatment response has become one of the most desirable goals. The current studies of lncRNA in oral cancer may facilitate the identification of valuable and convenient biomarkers to improve the diagnosis of high-risk patients with premalignant lesions or previous history of cancer. Encouragingly, recent investigations combined with statistics have identified multiple circulating lncRNAs detectable in blood and saliva harboring the potential to serve as non-invasive diagnostic and prognostic biomarkers for oral cancer. It is expected that more will be discovered in the near future, however, further extensive research, along with prospective studies with large cohorts, will be needed to validate these results and the performance of these biomarkers in oral cancer, to make liquid biopsy tests reliably translate into the clinic routine in oral cancer diagnostics.

In summary, our current knowledge has affirmed the pivotal role of lncRNAs in basic, translational, and clinical oral oncology. To fully explore the molecular mechanism and clinical applications of lncRNAs in oral cancer requires an advancement in analytical methodologies for deeper investigation and comprehension. Moreover, the integration of lncRNA profiling data in oral cancer using bioinformatics would enhance our understanding of regulatory signaling pathways in this malignancy. In the context of personalized medicine, it is anticipated that oral cancer-related lncRNAs will gain greater relevance and recognition, and we hope to see the rapid expansion of lncRNA-based clinical tools in the next decade, to significantly benefit oral cancer patients.

Author Contributions: C.-S.L., H.-J.K. and J.-W.S. wrote the manuscript. All authors have read and agreed to the published version of the manuscript.

Funding: This work was financially supported by grants MOST108-2321-B-010-013-MY2, MOST1082320-B-038-011 and MOST109-2320-B-038-064 from Ministry of Science and Technology of Taiwan (to H.-J.K.); TMU106-AE1-B52 from Taipei Medical University and MOST108-2320-B-038-009-MY2 from Ministry of Science and Technology of Taiwan (to J.-W.S.).

Acknowledgments: The authors acknowledge support from the Ministry of Science and Technology and Taipei Medical University for "Doctoral Education Scholarship to Encourage and Cultivate Talented Ph.D. Students with Outstanding Performance in Scientific Research" to Cing-Syuan Lei. We are immensely grateful to all the members of Kung and Shih labs for their valuable suggestions and feedback to our manuscript. The authors acknowledge Pei-Hsuan Tseng for her excellent graphic illustration support at TMU Research Promotion Center.

Conflicts of Interest: The authors declare no conflict of interest. 


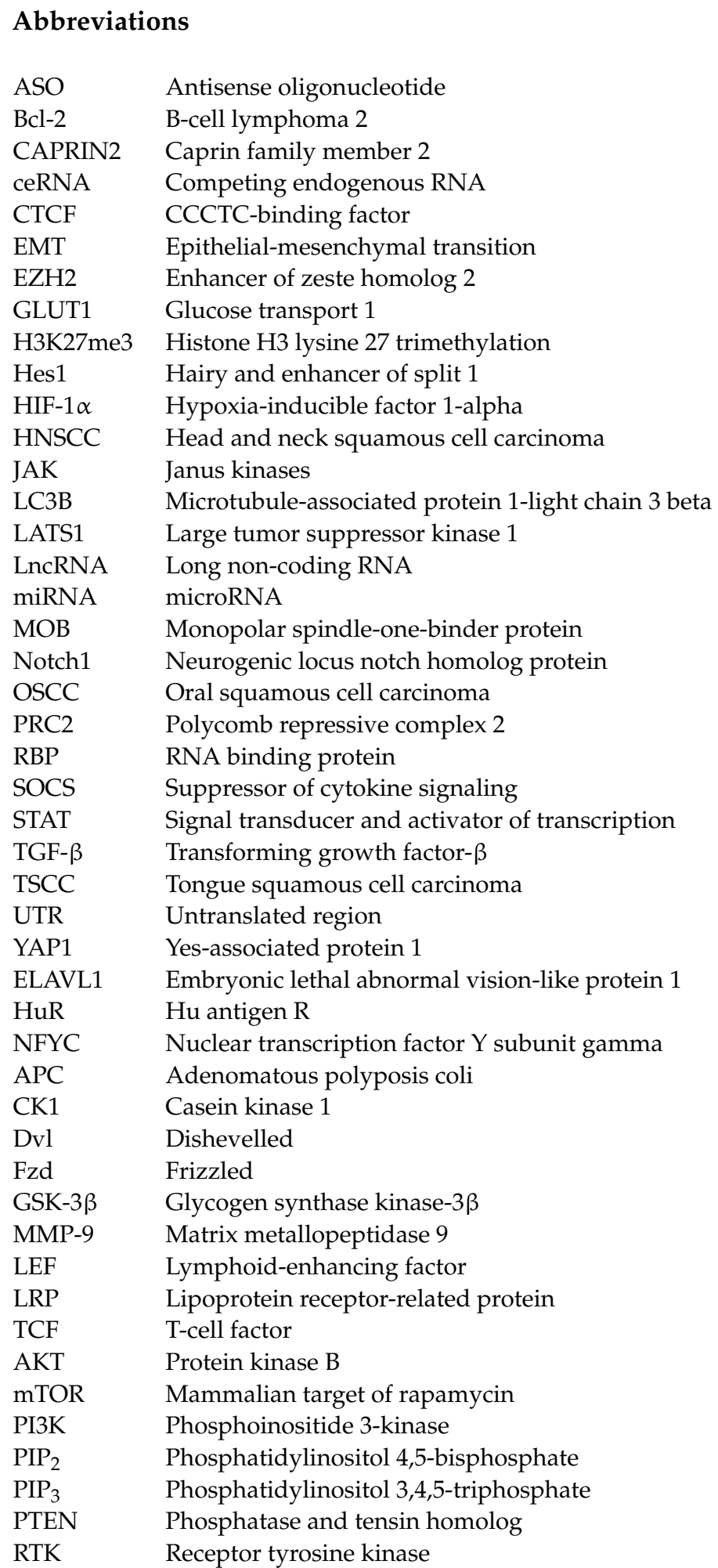

\section{References}

1. Sung, H.; Ferlay, J.; Siegel, R.L.; Laversanne, M.; Soerjomataram, I.; Jemal, A.; Bray, F. Global cancer statistics 2020: GLOBOCAN estimates of incidence and mortality worldwide for 36 cancers in 185 countries. CA Cancer J. Clin. 2018, 68, 394-424.

2. Forastiere, A.; Koch, W.; Trotti, A.; Sidransky, D. Head and Neck Cancer. N. Engl. J. Med. 2001, 345, 1890-1900. [CrossRef] [PubMed]

3. Zini, A.; Czerninski, R.; Sgan-Cohen, H.D. Oral cancer over four decades: Epidemiology, trends, histology, and survival by anatomical sites. J. Oral Pathol. Med. 2010, 39, 299-305. [CrossRef] [PubMed] 
4. Leung, L.L.; Riaz, M.K.; Qu, X.; Chan, J.; Meehan, K. Profiling of extracellular vesicles in oral cancer, from transcriptomics to proteomics. In Seminars in Cancer Biology; Academic Press: Cambridge, MA, USA, 2021.

5. Chen, Y.K.; Huang, H.C.; Lin, L.M.; Lin, C.C. Primary oral squamous cell carcinoma: An analysis of 703 cases in southern Taiwan. Oral Oncol. 1999, 35, 173-179. [CrossRef]

6. Bagan, J.; Sarrion, G.; Jimenez, Y. Oral cancer: Clinical features. Oral Oncol. 2010, 46, 414-417. [CrossRef]

7. Wang, W.; Han, S.; Yao, Z.; Li, X.; Huang, P.; Zhang, M.; Chen, Y.; He, J. A Study of Epidemiologic and Recurrence Factors of Oral Cancer. J. Oral Maxillofac. Surg. 2012, 70, 2205-2210. [CrossRef] [PubMed]

8. Johnson, D.E.; Burtness, B.; Leemans, C.R.; Lui, V.W.Y.; Bauman, J.E.; Grandis, J.R. Head and neck squamous cell carcinoma. Nat. Rev. Dis. Primers 2020, 6, 92. [CrossRef]

9. Thavarool, S.B.; Muttath, G.; Nayanar, S.; Duraisamy, K.; Bhat, P.; Shringarpure, K.; Nayak, P.; Tripathy, J.P.; Thaddeus, A.; Philip, S.B.S. Improved survival among oral cancer patients: Findings from a retrospective study at a tertiary care cancer centre in rural Kerala, India. World J. Surg. Oncol. 2019, 17, 15. [CrossRef]

10. Neville, B.W.; Day, T.A. Oral Cancer and Precancerous Lesions. CA A Cancer J. Clin. 2002, 52, 195-215. [CrossRef]

11. Alsahafi, E.; Begg, K.; Amelio, I.; Raulf, N.; Lucarelli, P.; Sauter, T.; Tavassoli, M. Clinical update on head and neck cancer: Molecular biology and ongoing challenges. Cell Death Dis. 2019, 10, 540. [CrossRef]

12. Uchida, S.; Dimmeler, S. Long Noncoding RNAs in Cardiovascular Diseases. Circ. Res. 2015, 116, 737-750. [CrossRef]

13. Statello, L.; Guo, C.-J.; Chen, L.-L.; Huarte, M. Gene regulation by long non-coding RNAs and its biological functions. Nat. Rev. Mol. Cell Biol. 2021, 22, 96-118. [CrossRef]

14. Wu, X.; Tudoran, O.M.; Calin, G.A.; Ivan, M. The Many Faces of Long Noncoding RNAs in Cancer. Antioxid. Redox Signal. 2017, 29, 922-935. [CrossRef]

15. Dahariya, S.; Paddibhatla, I.; Kumar, S.; Raghuwanshi, S.; Pallepati, A.; Gutti, R.K. Long non-coding RNA: Classification, biogenesis and functions in blood cells. Mol. Immunol. 2019, 112, 82-92. [CrossRef]

16. Kuo, T.-C.; Kung, H.-J.; Shih, J.-W. Signaling in and out: Long-noncoding RNAs in tumor hypoxia. J. Biomed. Sci. 2020, 27, 59. [CrossRef] [PubMed]

17. Nohata, N.; Abba, M.C.; Gutkind, J.S. Unraveling the oral cancer lncRNAome: Identification of novel lncRNAs associated with malignant progression and HPV infection. Oral. Oncol. 2016, 59, 58-66. [CrossRef] [PubMed]

18. Pentenero, M.; Bowers, L.M.; Jayasinghe, R.; Yap, T.; Cheong, S.C.; Kerr, A.R.; Farah, C.S.; Alevizos, I. World Workshop on Oral Medicine VII: Clinical evidence of differential expression of lncRNAs in oral squamous cell carcinoma: A scoping review. Oral Dis. 2019, 25 (Suppl. 1), 88-101. [CrossRef]

19. Pentenero, M.; Bowers, L.; Jayasinghe, R.; Cheong, S.C.; Farah, C.S.; Kerr, A.R.; Alevizos, I. World Workshop on Oral Medicine VII: Functional pathways involving differentially expressed lncRNAs in oral squamous cell carcinoma. Oral Dis. 2019, 25 (Suppl. 1), 79-87. [CrossRef]

20. Zhang, L.; Meng, X.; Zhu, X.W.; Yang, D.C.; Chen, R.; Jiang, Y.; Xu, T. Long non-coding RNAs in Oral squamous cell carcinoma: Biologic function, mechanisms and clinical implications. Mol. Cancer 2019, 18, 102. [CrossRef] [PubMed]

21. Zhang, K.; Qiu, W.; Wu, B.; Fang, F. Long non-coding RNAs are novel players in oral inflammatory disorders, potentially premalignant oral epithelial lesions and oral squamous cell carcinoma (Review). Int. J. Mol. Med. 2020, 46, 535-545. [CrossRef] [PubMed]

22. Xu, Y.; Jiang, E.; Shao, Z.; Shang, Z. Long Noncoding RNAs in the Metastasis of Oral Squamous Cell Carcinoma. Front. Oncol. 2021, 10, 3014. [CrossRef]

23. Palazzo, A.F.; Koonin, E.V. Functional Long Non-coding RNAs Evolve from Junk Transcripts. Cell 2020, 183, 1151-1161. [CrossRef] [PubMed]

24. Lu, T.; Liu, H.; You, G. Long non-coding RNA C5orf66-AS1 prevents oral squamous cell carcinoma through inhibiting cell growth and metastasis. Int. J. Mol. Med. 2018, 42, 3291-3299. [CrossRef]

25. Xing, H.B.; Qiu, H.M.; Li, Y.; Dong, P.F.; Zhu, X.M. Long noncoding RNA CASC2 alleviates the growth, migration and invasion of oral squamous cell carcinoma via downregulating CDK1. Eur. Rev. Med. Pharmacol. Sci. 2019, 23, 4777-4783.

26. Dong, Y.; Wu, W. Downregulation of lncRNA CASC2 promotes the postoperative local recurrence of early oral squamous cell carcinoma. Eur. Arch. Otorhinolaryngol. 2019, 276, 605-610. [CrossRef] [PubMed]

27. Pan, L.; Chen, H.; Bai, Y.; Wang, Q.; Chen, L. Long non-coding RNA CASC2 serves as a ceRNA of microRNA-21 to promote PDCD4 expression in oral squamous cell carcinoma. Onco. Targets Ther. 2019, 12, 3377-3385. [CrossRef] [PubMed]

28. Chen, F.; Yan, L.; Wang, J.; Lin, L.; Qiu, Y.; Hu, Z.; Wu, J.; Bao, X.; Lin, L.; Wang, R.; et al. Upregulated long noncoding RNA ENST00000470447.1 inhibits cell migration and invasion and predicts better disease-free survival of oral cancer. Head Neck 2019, 41, 2883-2891. [CrossRef]

29. Jia, B.; Xie, T.; Qiu, X.; Sun, X.; Chen, J.; Huang, Z.; Zheng, X.; Wang, Z.; Zhao, J. Long noncoding RNA FALEC inhibits proliferation and metastasis of tongue squamous cell carcinoma by epigenetically silencing ECM1 through EZH2. Aging 2019, 11, 4990-5007. [CrossRef]

30. Chen, F.B.; Wu, P.; Zhou, R.; Yang, Q.X.; Zhang, X.; Wang, R.R.; Qi, S.C.; Yang, X. LINC01315 Impairs microRNA-211-Dependent DLG3 Downregulation to Inhibit the Development of Oral Squamous Cell Carcinoma. Front. Oncol. 2020, 10, 556084. [CrossRef]

31. Jin, Z.; Jiang, S.; Jian, S.; Shang, Z. Long noncoding RNA MORT overexpression inhibits cancer cell proliferation in oral squamous cell carcinoma by downregulating ROCK1. J. Cell Biochem. 2019, 120, 11702-11707. [CrossRef] 
32. Wu, Y.; Zhang, L.; Zhang, L.; Wang, Y.; Li, H.; Ren, X.; Wei, F.; Yu, W.; Liu, T.; Wang, X.; et al. Long non-coding RNA HOTAIR promotes tumor cell invasion and metastasis by recruiting EZH2 and repressing E-cadherin in oral squamous cell carcinoma. Int. J. Oncol. 2015, 46, 2586-2594. [CrossRef]

33. Gupta, R.A.; Shah, N.; Wang, K.C.; Kim, J.; Horlings, H.M.; Wong, D.J.; Tsai, M.C.; Hung, T.; Argani, P.; Rinn, J.L.; et al. Long non-coding RNA HOTAIR reprograms chromatin state to promote cancer metastasis. Nature 2010, 464, 1071-1076. [CrossRef]

34. Tsai, M.C.; Manor, O.; Wan, Y.; Mosammaparast, N.; Wang, J.K.; Lan, F.; Shi, Y.; Segal, E.; Chang, H.Y. Long noncoding RNA as modular scaffold of histone modification complexes. Science 2010, 329, 689-693. [CrossRef]

35. Lu, M.Y.; Liao, Y.W.; Chen, P.Y.; Hsieh, P.L.; Fang, C.Y.; Wu, C.Y.; Yen, M.L.; Peng, B.Y.; Wang, D.P.; Cheng, H.C.; et al. Targeting LncRNA HOTAIR suppresses cancer stemness and metastasis in oral carcinomas stem cells through modulation of EMT Oncotarget 2017, 8, 98542-98552. [CrossRef]

36. Wang, X.; Liu, W.; Wang, P.; Li, S. RNA interference of long noncoding RNA HOTAIR suppresses autophagy and promotes apoptosis and sensitivity to cisplatin in oral squamous cell carcinoma. J. Oral Pathol. Med. 2018, 47, 930-937. [CrossRef]

37. Tao, D.; Zhang, Z.; Liu, X.; Zhang, Z.; Fu, Y.; Zhang, P.; Yuan, H.; Liu, L.; Cheng, J.; Jiang, H. LncRNA HOTAIR promotes the invasion and metastasis of oral squamous cell carcinoma through metastasis-associated gene 2. Mol. Carcinog. 2020, 59, 353-364. [CrossRef]

38. Pisignano, G.; Pavlaki, I.; Murrell, A. Being in a loop: How long non-coding RNAs organise genome architecture. Essays Biochem. 2019, 63, 177-186. [PubMed]

39. Ai, Y.; Wu, S.; Zou, C.; Wei, H. LINC00941 promotes oral squamous cell carcinoma progression via activating CAPRIN2 and canonical WNT/ $\beta$-catenin signaling pathway. J. Cell Mol. Med. 2020, 24, 10512-10524. [CrossRef] [PubMed]

40. Wang, Y.; Zhang, X.; Wang, Z.; Hu, Q.; Wu, J.; Li, Y.; Ren, X.; Wu, T.; Tao, X.; Chen, X.; et al. LncRNA-p23154 promotes the invasion-metastasis potential of oral squamous cell carcinoma by regulating Glut1-mediated glycolysis. Cancer Lett. 2018, 434, 172-183. [CrossRef] [PubMed]

41. Zhu, G.; Wang, S.; Chen, J.; Wang, Z.; Liang, X.; Wang, X.; Jiang, J.; Lang, J.; Li, L. Long noncoding RNA HAS2-AS1 mediates hypoxia-induced invasiveness of oral squamous cell carcinoma. Mol. Carcinog. 2017, 56, 2210-2222. [CrossRef] [PubMed]

42. Vigetti, D.; Deleonibus, S.; Moretto, P.; Bowen, T.; Fischer, J.W.; Grandoch, M.; Oberhuber, A.; Love, D.C.; Hanover, J.A.; Cinquetti, R.; et al. Natural Antisense Transcript for Hyaluronan Synthase 2 (HAS2-AS1) Induces Transcription of HAS2 via Protein O-GlcNAcylation*. J. Biol. Chem. 2014, 289, 28816-28826. [CrossRef] [PubMed]

43. Shih, J.W.; Chiang, W.F.; Wu, A.T.H.; Wu, M.H.; Wang, L.Y.; Yu, Y.L.; Hung, Y.W.; Wang, W.C.; Chu, C.Y.; Hung, C.L.; et al. Long noncoding RNA LncHIFCAR/MIR31HG is a HIF- $1 \alpha$ co-activator driving oral cancer progression. Nat. Commun 2017, 8, 15874 [CrossRef] [PubMed]

44. Wang, R.; Ma, Z.; Feng, L.; Yang, Y.; Tan, C.; Shi, Q.; Lian, M.; He, S.; Ma, H.; Fang, J. LncRNA MIR31HG targets HIF1A and P21 to facilitate head and neck cancer cell proliferation and tumorigenesis by promoting cell-cycle progression. Mol. Cancer 2018, 17, 162. [CrossRef]

45. Feng, L.; Wang, R.; Lian, M.; Ma, H.; He, N.; Liu, H.; Wang, H.; Fang, J. Integrated Analysis of Long Noncoding RNA and mRNA Expression Profile in Advanced Laryngeal Squamous Cell Carcinoma. PLOS ONE 2016, 11, e0169232. [CrossRef] [PubMed]

46. Sigova, A.A.; Mullen, A.C.; Molinie, B.; Gupta, S.; Orlando, D.A.; Guenther, M.G.; Almada, A.E.; Lin, C.; Sharp, P.A.; Giallourakis, C.C.; et al. Divergent transcription of long noncoding RNA/mRNA gene pairs in embryonic stem cells. Proc. Natl. Acad. Sci. USA 2013, 110, 2876-2881. [CrossRef] [PubMed]

47. Romero-Barrios, N.; Legascue, M.F.; Benhamed, M.; Ariel, F.; Crespi, M. Splicing regulation by long noncoding RNAs. Nucleic Acids Res. 2018, 46, 2169-2184. [CrossRef] [PubMed]

48. Guo, Y.; Ma, Y.; Hu, X.; Song, R.; Zhu, L.; Zhong, M. Long non-coding RNA CEBPA-AS1 correlates with poor prognosis and promotes tumorigenesis via CEBPA/Bcl2 in oral squamous cell carcinoma. Cancer Biol. Ther. 2018, 19, 205-213. [CrossRef]

49. Salmena, L.; Poliseno, L.; Tay, Y.; Kats, L.; Pandolfi, P.P. A ceRNA hypothesis: The Rosetta Stone of a hidden RNA language? Cell 2011, 146, 353-358. [CrossRef]

50. Denzler, R.; Agarwal, V.; Stefano, J.; Bartel, D.P.; Stoffel, M. Assessing the ceRNA hypothesis with quantitative measurements of miRNA and target abundance. Mol. Cell 2014, 54, 766-776. [CrossRef]

51. Denzler, R.; McGeary, S.E.; Title, A.C.; Agarwal, V.; Bartel, D.P.; Stoffel, M. Impact of MicroRNA Levels, Target-Site Complementarity, and Cooperativity on Competing Endogenous RNA-Regulated Gene Expression. Mol. Cell 2016, 64, 565-579. [CrossRef]

52. Thomson, D.W.; Dinger, M.E. Endogenous microRNA sponges: Evidence and controversy. Nat. Rev. Genet. 2016, 17, 272-283. [CrossRef] [PubMed]

53. Wu, K.; Jiang, Y.; Zhou, W.; Zhang, B.; Li, Y.; Xie, F.; Zhang, J.; Wang, X.; Yan, M.; Xu, Q.; et al. Long Noncoding RNA RC3H2 Facilitates Cell Proliferation and Invasion by Targeting MicroRNA-101-3p/EZH2 Axis in OSCC. Mol. Ther. Nucleic Acids 2020, 20, 97-110. [CrossRef]

54. Wu, J.; Zhao, W.; Wang, Z.; Xiang, X.; Zhang, S.; Liu, L. Long non-coding RNA SNHG20 promotes the tumorigenesis of oral squamous cell carcinoma via targeting miR-197/LIN28 axis. J. Cell Mol. Med. 2019, 23, 680-688. [CrossRef] [PubMed]

55. Yang, Q.; Sun, H.; Wang, X.; Yu, X.; Zhang, J.; Guo, B.; Hexige, S. Metabolic changes during malignant transformation in primary cells of oral lichen planus: Succinate accumulation and tumour suppression. J. Cell Mol. Med. 2020, 24, 1179-1188. [CrossRef] [PubMed] 
56. Chai, L.; Yuan, Y.; Chen, C.; Zhou, J.; Wu, Y. The role of long non-coding RNA ANRIL in the carcinogenesis of oral cancer by targeting miR-125a. Biomed. Pharmacother. 2018, 103, 38-45. [CrossRef]

57. Ge, C.; Dong, J.; Chu, Y.; Cao, S.; Zhang, J.; Wei, J. LncRNA FGD5-AS1 promotes tumor growth by regulating MCL1 via sponging miR-153-3p in oral cancer. Aging 2020, 12, 14355-14364. [CrossRef]

58. Hong, Y.; He, H.; Sui, W.; Zhang, J.; Zhang, S.; Yang, D. Long non-coding RNA H19 promotes cell proliferation and invasion by acting as a ceRNA of miR-138 and releasing EZH2 in oral squamous cell carcinoma. Int. J. Oncol 2018, 52, 901-912. [CrossRef]

59. Chang, S.M.; Hu, W.W. Long non-coding RNA MALAT1 promotes oral squamous cell carcinoma development via microRNA125b/STAT3 axis. J. Cell Physiol. 2018, 233, 3384-3396. [CrossRef]

60. Sun, C.C.; Zhang, L.; Li, G.; Li, S.J.; Chen, Z.L.; Fu, Y.F.; Gong, F.Y.; Bai, T.; Zhang, D.Y.; Wu, Q.M.; et al. The lncRNA PDIA3P Interacts with miR-185-5p to Modulate Oral Squamous Cell Carcinoma Progression by Targeting Cyclin D2. Mol. Ther. Nucleic Acids 2017, 9, 100-110. [CrossRef]

61. Li, C.; Ye, J.; Zhang, Z.; Gong, Z.; Lin, Z.; Ding, M. Long non-coding RNA RBM5-AS1 promotes the aggressive behaviors of oral squamous cell carcinoma by regulation of miR-1285-3p/YAP1 axis. Biomed. Pharmacother. 2020, 123, 109723. [CrossRef]

62. Liu, S.; Liu, L.H.; Hu, W.W.; Wang, M. Long noncoding RNA TUG1 regulates the development of oral squamous cell carcinoma through sponging miR-524-5p to mediate DLX1 expression as a competitive endogenous RNA. J. Cell Physiol. 2019, 234, 20206-20216. [CrossRef]

63. Fu, S.W.; Zhang, Y.; Li, S.; Shi, Z.Y.; Zhao, J.; He, Q.L. LncRNA TTN-AS1 promotes the progression of oral squamous cell carcinoma via miR-411-3p/NFAT5 axis. Cancer Cell Int. 2020, 20, 415. [CrossRef]

64. He, R.Z.; Luo, D.X.; Mo, Y.Y. Emerging roles of lncRNAs in the post-transcriptional regulation in cancer. Genes Dis. 2019, 6, 6-15. [CrossRef]

65. Wu, X.; Gardashova, G.; Lan, L.; Han, S.; Zhong, C.; Marquez, R.T.; Wei, L.; Wood, S.; Roy, S.; Gowthaman, R.; et al. Targeting the interaction between RNA-binding protein HuR and FOXQ1 suppresses breast cancer invasion and metastasis. Commun. Biol. 2020, 3, 193. [CrossRef] [PubMed]

66. Liu, Z; Tao, H. Small nucleolar RNA host gene 3 facilitates cell proliferation and migration in oral squamous cell carcinoma via targeting nuclear transcription factor Y subunit gamma. J. Cell Biochem. 2020, 121, 2150-2158. [CrossRef] [PubMed]

67. Wu, P.; Mo, Y.; Peng, M.; Tang, T.; Zhong, Y.; Deng, X.; Xiong, F.; Guo, C.; Wu, X.; Li, Y.; et al. Emerging role of tumor-related functional peptides encoded by lncRNA and circRNA. Mol. Cancer 2020, 19, 22. [CrossRef] [PubMed]

68. Ruiz-Orera, J.; Villanueva-Cañas, J.L.; Albà, M.M. Evolution of new proteins from translated sORFs in long non-coding RNAs. Exp. Cell Res. 2020, 391, 111940. [CrossRef]

69. Shao, T.; Huang, J.; Zheng, Z.; Wu, Q.; Liu, T.; Lv, X. SCCA, TSGF, and the Long Non-Coding RNA AC007271.3 are Effective Biomarkers for Diagnosing Oral Squamous Cell Carcinoma. Cell Physiol. Biochem. 2018, 47, 26-38. [CrossRef]

70. Shao, T.R.; Zheng, Z.N.; Chen, Y.C.; Wu, Q.Q.; Huang, G.Z.; Li, F.; Zeng, W.S.; Lv, X.Z. LncRNA AC007271.3 promotes cell proliferation, invasion, migration and inhibits cell apoptosis of OSCC via the Wnt/ $\beta$-catenin signaling pathway. Life Sci. 2019, 239, 117087. [CrossRef]

71. Liu, L.; Ning, S.B.; Fu, S.; Mao, Y.; Xiao, M.; Guo, B. Effects of lncRNA ANRIL on proliferation and apoptosis of oral squamous cell carcinoma cells by regulating TGF- $\beta$ /Smad pathway. Eur. Rev. Med. Pharmacol. Sci. 2019, 23, 6194-6201.

72. Zhang, D.; Ding, L.; Li, Y.; Ren, J.; Shi, G.; Wang, Y.; Zhao, S.; Ni, Y.; Hou, Y. Midkine derived from cancer-associated fibroblasts promotes cisplatin-resistance via up-regulation of the expression of lncRNA ANRIL in tumour cells. Sci Rep. 2017, 7, 16231. [CrossRef] [PubMed]

73. Huang, W.; Zhou, R.; Mao, L.; Deng, C.; Dang, X. Esophageal cancer related gene-4 inhibits the migration and proliferation of oral squamous cell carcinoma through BC200 lncRNA/MMP-9 and -13 signaling pathway. Cell Signal. 2019, 62, 109327. [CrossRef] [PubMed]

74. Dai, D.; Feng, X.D.; Zhu, W.Q.; Bao, Y.N. LncRNA BLACAT1 regulates the viability, migration and invasion of oral squamous cell carcinoma cells by targeting miR-142-5p. Eur. Rev. Med. Pharmacol. Sci. 2019, 23, 10313-10323. [PubMed]

75. Yang, Y.; Chen, D.; Liu, H.; Yang, K. Increased expression of lncRNA CASC9 promotes tumor progression by suppressing autophagy-mediated cell apoptosis via the AKT/mTOR pathway in oral squamous cell carcinoma. Cell Death Dis. 2019, 10, 41. [CrossRef]

76. Zhang, X.; Guo, B.; Zhu, Y.; Xu, W.; Ning, S.; Liu, L. Up-regulation of plasma lncRNA CACS15 distinguished early-stage oral squamous cell carcinoma patient. Oral Dis. 2020, 26, 1619-1624. [CrossRef]

77. Arunkumar, G.; Murugan, A.K.; Prasanna Srinivasa Rao, H.; Subbiah, S.; Rajaraman, R.; Munirajan, A.K. Long non-coding RNA CCAT1 is overexpressed in oral squamous cell carcinomas and predicts poor prognosis. Biomed. Rep. 2017, 6, 455-462. [CrossRef]

78. Li, G.H.; Ma, Z.H.; Wang, X. Long non-coding RNA CCAT1 is a prognostic biomarker for the progression of oral squamous cell carcinoma via miR-181a-mediated Wnt/ $\beta$-catenin signaling pathway. Cell Cycle 2019, 18, 2902-2913. [CrossRef]

79. Wang, Y.; Tong, J.; Lin, H.; Ma, L.; Xu, Y. CCHE1 accelerated the initiation of oral squamous cell carcinoma through enhancing PAK2 expression by sponging miR-922. J. Oral Pathol. Med. 2020, 49, 636-644. [CrossRef]

80. Dai, J.; Mu, J.W.; Mu, H. Long non-coding RNA CRNDE regulates cell proliferation, migration, invasion, epithelial-mesenchymal transition and apoptosis in oral squamous cell carcinoma. Oncol. Lett. 2019, 17, 3330-3340. [CrossRef]

81. Qu, X.H.; Shi, Y.L.; Ma, Y.; Bao, W.W.; Yang, L.; Li, J.C.; Zhang, F. LncRNA DANCR regulates the growth and metastasis of oral squamous cell carcinoma cells via altering miR-216a-5p expression. Hum. Cell 2020, 33, 1281-1293. [CrossRef] 
82. Fang, X.; Tang, Z.; Zhang, H.; Quan, H. Long non-coding RNA DNM3OS/miR-204-5p/HIP1 axis modulates oral cancer cell viability and migration. J. Oral Pathol. Med. 2020, 49, 865-875. [CrossRef] [PubMed]

83. Chu, H.; Li, Z.; Gan, Z.; Yang, Z.; Wu, Z.; Rong, M. LncRNA ELF3-AS1 is involved in the regulation of oral squamous cell carcinoma cell proliferation by reprogramming glucose metabolism. Onco Targets Ther. 2019, 12, 6857-6863. [CrossRef] [PubMed]

84. Ye, J.; Jiao, Y. LncRNA FAL1 promotes the development of oral squamous cell carcinoma through regulating the microRNA761/CRKL pathway. Eur. Rev. Med. Pharmacol. Sci. 2019, 23, 5779-5786.

85. Liu, L.; Zhan, Y.; Huang, Y.; Huang, L. LncRNA FGD5-AS1 can be predicted as therapeutic target in oral cancer. J. Oral Pathol. Med. 2020, 49, 243-252. [CrossRef] [PubMed]

86. Yang, M.; Xiong, X.; Chen, L.; Yang, L.; Li, X. Identification and validation long non-coding RNAs of oral squamous cell carcinoma by bioinformatics method. Oncotarget 2017, 8, 107469-107476. [CrossRef] [PubMed]

87. Zeng, B.; Li, Y.; Jiang, F.; Wei, C.; Chen, G.; Zhang, W.; Zhao, W.; Yu, D. LncRNA GAS5 suppresses proliferation, migration, invasion, and epithelial-mesenchymal transition in oral squamous cell carcinoma by regulating the miR-21/PTEN axis. Exp. Cell Res. 2019, 374, 365-373. [CrossRef]

88. Zhao, J.; Bai, X.; Feng, C.; Shang, X.; Xi, Y. Long Non-Coding RNA HCP5 Facilitates Cell Invasion And Epithelial-Mesenchymal Transition In Oral Squamous Cell Carcinoma By miR-140-5p/SOX4 Axis. Cancer Manag. Res. 2019, 11, 10455-10462. [CrossRef]

89. Liu, Z.; Li, H.; Fan, S.; Lin, H.; Lian, W. STAT3-induced upregulation of long noncoding RNA HNF1A-AS1 promotes the progression of oral squamous cell carcinoma via activating Notch signaling pathway. Cancer Biol Ther 2019, $20,444-453$. [CrossRef]

90. Xiong, L.; Tang, Y.; Tang, J.; Liu, Z.; Wang, X. Downregulation of lncRNA HOTTIP Suppresses the Proliferation, Migration, and Invasion of Oral Tongue Squamous Cell Carcinoma by Regulation of HMGA2-Mediated Wnt/ $\beta$-Catenin Pathway. Cancer Biother. Radiopharm. 2020, 35, 720-730. [CrossRef]

91. Mu, M.; Li, Y.; Zhan, Y.; Li, X.; Zhang, B. Knockdown of HOXA transcript at the distal tip suppresses the growth and invasion and induces apoptosis of oral tongue squamous carcinoma cells. Onco Targets Ther. 2018, 11, 8033-8044. [CrossRef]

92. Li, B.; Wang, W.; Miao, S.; Li, G.; Lv, Y.; Xiang, C.; Pei, R. HOXA11-AS promotes the progression of oral squamous cell carcinoma by targeting the miR-518a-3p/PDK1 axis. Cancer Cell Int. 2019, 19, 140. [CrossRef]

93. Wang, X.; Li, H.; Shi, J. LncRNA HOXA11-AS Promotes Proliferation and Cisplatin Resistance of Oral Squamous Cell Carcinoma by Suppression of miR-214-3p Expression. Biomed. Res. Int 2019, 2019, 8645153. [CrossRef] [PubMed]

94. Niu, X.; Yang, B.; Liu, F.; Fang, Q. LncRNA HOXA11-AS promotes OSCC progression by sponging miR-98-5p to upregulate YBX2 expression. Biomed. Pharmacother. 2020, 121, 109623. [CrossRef]

95. Li, W.; Zhu, Q.; Zhang, S.; Liu, L.; Zhang, H.; Zhu, D. HOXC13-AS accelerates cell proliferation and migration in oral squamous cell carcinoma via miR-378g/HOXC13 axis. Oral Oncol. 2020, 111, 104946. [CrossRef] [PubMed]

96. Su, W.; Tang, J.; Wang, Y.; Sun, S.; Shen, Y.; Yang, H. Long non-coding RNA highly up-regulated in liver cancer promotes epithelial-to-mesenchymal transition process in oral squamous cell carcinoma. J. Cell Mol. Med. 2019, 23, 2645-2655. [CrossRef] [PubMed]

97. Yao, Y.; Chen, S.; Lu, N.; Yin, Y.; Liu, Z. LncRNA JPX overexpressed in oral squamous cell carcinoma drives malignancy via miR-944/CDH2 axis. Oral Dis. 2021, 27, 924-933. [CrossRef]

98. Zhang, C.; Bao, C.; Zhang, X.; Lin, X.; Pan, D.; Chen, Y. Knockdown of lncRNA LEF1-AS1 inhibited the progression of oral squamous cell carcinoma (OSCC) via Hippo signaling pathway. Cancer Biol. Ther. 2019, 20, 1213-1222. [CrossRef]

99. Li, M.; Ning, J.; Li, Z.; Wang, J.; Zhao, C.; Wang, L. LINC00152 promotes the growth and invasion of oral squamous cell carcinoma by regulating miR-139-5p. Onco Targets Ther. 2018, 11, 6295-6304. [CrossRef]

100. Jiang, X.; Liu, J.; Li, S.; Jia, B.; Huang, Z.; Shen, J.; Luo, H.; Zhao, J. CCL18-induced LINC00319 promotes proliferation and metastasis in oral squamous cell carcinoma via the miR-199a-5p/FZD4 axis. Cell Death Dis. 2020, 11, 777. [CrossRef]

101. Wang, Z.; Zhu, X.; Dong, P.; Cai, J. Long noncoding RNA LINC00958 promotes the oral squamous cell carcinoma by sponging miR-185-5p/YWHAZ. Life Sci. 2020, 242, 116782. [CrossRef]

102. Lee, S.P.; Hsieh, P.L.; Fang, C.Y.; Chu, P.M.; Liao, Y.W.; Yu, C.H.; Yu, C.C.; Tsai, L.L. LINC00963 Promotes Cancer Stemness, Metastasis, and Drug Resistance in Head and Neck Carcinomas via ABCB5 Regulation. Cancers 2020, 12, 1073. [CrossRef] [PubMed]

103. Jin, T.; Guo, Y.; Huang, Z.; Zhang, Q.; Huang, Z.; Zhang, Y.; Huang, Z. Vitamin D inhibits the proliferation of Oral Squamous Cell Carcinoma by suppressing lncRNA LUCAT1 through the MAPK pathway. J. Cancer 2020, 11, 5971-5981. [CrossRef]

104. Zhu, M.; Zhang, C.; Chen, D.; Chen, S.; Zheng, H. lncRNA MALAT1 potentiates the progression of tongue squamous cell carcinoma through regulating miR-140-5p-PAK1 pathway. Onco. Targets Ther. 2019, 12, 1365-1377. [CrossRef]

105. Xiao, L.; Wang, W.; Zhao, J.; Xu, H.; Li, S.; Yang, X. lncRNA MALAT1 promotes cell proliferation and invasion by regulating the miR-101/EZH2 axis in oral squamous cell carcinoma. Oncol. Lett. 2020, 20, 164. [CrossRef]

106. Yu, L.; Shao, X.; Huo, L.; Zhang, T. Long Non-Coding RNA (lncRNA) Metastasis-Associated Lung Adenocarcinoma Transcript 1 (MALAT1) Promotes Cell Proliferation and Migration by Regulating miR-143-3p and MAGE Family Member A9 (MAGEA9) in Oral Squamous Cell Carcinoma. Med. Sci. Monit. 2020, 26, e924187. [CrossRef]

107. Liang, J.; Liang, L.; Ouyang, K.; Li, Z.; Yi, X. MALAT1 induces tongue cancer cells' EMT and inhibits apoptosis through Wnt/ $\beta$-catenin signaling pathway. J. Oral Pathol. Med. 2017, 46, 98-105. [CrossRef] 
108. Wang, R.; Lu, X.; Yu, R. lncRNA MALAT1 Promotes EMT Process and Cisplatin Resistance of Oral Squamous Cell Carcinoma via PI3K/AKT/m-TOR Signal Pathway. Onco. Targets Ther. 2020, 13, 4049-4061. [CrossRef]

109. Hou, C.; Wang, X.; Du, B. lncRNA MCM3AP-AS1 promotes the development of oral squamous cell carcinoma by inhibiting miR-363-5p. Exp. Ther. Med. 2020, 20, 978-984. [CrossRef]

110. Li, H.; Jiang, J. LncRNA MCM3AP-AS1 promotes proliferation, migration and invasion of oral squamous cell carcinoma cells via regulating miR-204-5p/FOXC1. J. Investig. Med. 2020, 68, 1282-1288. [CrossRef] [PubMed]

111. Zhang, L.L.; Hu, D.; Zou, L.H. Low expression of lncRNA MEG3 promotes the progression of oral squamous cell carcinoma by targeting miR-21. Eur. Rev. Med. Pharmacol. Sci. 2018, 22, 8315-8323. [PubMed]

112. Tan, J.; Xiang, L.; Xu, G. LncRNA MEG3 suppresses migration and promotes apoptosis by sponging miR-548d-3p to modulate JAK-STAT pathway in oral squamous cell carcinoma. IUBMB Life 2019, 71, 882-890. [CrossRef] [PubMed]

113. Liu, Z.; Wu, C.; Xie, N.; Wang, P. Long non-coding RNA MEG3 inhibits the proliferation and metastasis of oral squamous cell carcinoma by regulating the WNT/ $\beta$-catenin signaling pathway. Oncol. Lett. 2017, 14, 4053-4058. [CrossRef] [PubMed]

114. Zhang, S.; Li, C.; Liu, J.; Geng, F.; Shi, X.; Li, Q.; Lu, Z.; Pan, Y. Fusobacterium nucleatum promotes epithelial-mesenchymal transiton through regulation of the lncRNA MIR4435-2HG/miR-296-5p/Akt2/SNAI1 signaling pathway. FEBS J. 2020, 287, 4032-4047. [CrossRef] [PubMed]

115. Xiong, H.G.; Li, H.; Xiao, Y.; Yang, Q.C.; Yang, L.L.; Chen, L.; Bu, L.L.; Zhang, W.F.; Zhang, J.L.; Sun, Z.J. Long noncoding RNA MYOSLID promotes invasion and metastasis by modulating the partial epithelial-mesenchymal transition program in head and neck squamous cell carcinoma. J. Exp. Clin. Cancer Res. 2019, 38, 278. [CrossRef] [PubMed]

116. Huang, G.; He, X.; Wei, X.L. lncRNA NEAT1 promotes cell proliferation and invasion by regulating miR-365/RGS20 in oral squamous cell carcinoma. Oncol. Rep. 2018, 39, 1948-1956. [CrossRef]

117. Arunkumar, G.; Anand, S.; Raksha, P.; Dhamodharan, S.; Prasanna Srinivasa Rao, H.; Subbiah, S.; Murugan, A.K.; Munirajan, A.K. LncRNA OIP5-AS1 is overexpressed in undifferentiated oral tumors and integrated analysis identifies as a downstream effector of stemness-associated transcription factors. Sci. Rep. 2018, 8, 7018. [CrossRef]

118. Li, M.; Ning, J.; Li, Z.; Fei, Q.; Zhao, C.; Ge, Y.; Wang, L. Long noncoding RNA OIP5-AS1 promotes the progression of oral squamous cell carcinoma via regulating miR-338-3p/NRP1 axis. Biomed. Pharmacother. 2019, 118, 109259. [CrossRef]

119. Zhang, P.; Liu, Y.; Li, C.; Zhang, L.; Liu, Q.; Jiang, T. LncRNA PAPAS promotes oral squamous cell carcinoma by upregulating transforming growth factor- $\beta 1$. J. Cell Biochem. 2019, 120, 16120-16127. [CrossRef]

120. Chen, F.; Qi, S.; Zhang, X.; Wu, J.; Yang, X.; Wang, R. lncRNA PLAC2 activated by H3K27 acetylation promotes cell proliferation and invasion via the activation of Wnt/ $\beta$-catenin pathway in oral squamous cell carcinoma. Int. J. Oncol. 2019, 54, 1183-1194 [CrossRef]

121. Li, X.; Ren, H. Long noncoding RNA PVT1 promotes tumor cell proliferation, invasion, migration and inhibits apoptosis in oral squamous cell carcinoma by regulating miR-150-5p/GLUT-1. Oncol Rep. 2020, 44, 1524-1538. [CrossRef] [PubMed]

122. Wang, F.; Ji, X.; Wang, J.; Ma, X.; Yang, Y.; Zuo, J.; Cui, J. LncRNA PVT1 Enhances Proliferation and Cisplatin Resistance via Regulating miR-194-5p/HIF1a Axis in Oral Squamous Cell Carcinoma. Onco Targets Ther. 2020, 13, 243-252. [CrossRef]

123. Liu, G.M.; Lu, T.C.; Sun, M.L.; Ji, X.; Zhao, Y.A.; Jia, W.Y.; Luo, Y.G. RP11-874J12.4 promotes oral squamous cell carcinoma tumorigenesis via the miR-19a-5p/EBF1 axis. J. Oral Pathol. Med. 2020, 49, 645-654. [CrossRef]

124. Yin, Y.; Tan, Y.; Yao, Y.; Lu, N.; Zhang, F. SNHG12/miR-326/E2F1 feedback loop facilitates the progression of oral squamous cell carcinoma. Oral Dis. 2020, 26, 1631-1639. [CrossRef] [PubMed]

125. Tong, F.; Guo, J.; Miao, Z.; Li, Z. LncRNA SNHG17 promotes the progression of oral squamous cell carcinoma by modulating miR-375/PAX6 axis. Cancer Biomark. 2021, 30, 1-12. [CrossRef]

126. Gao, P.; Fan, R.; Ge, T. SNHG20 serves as a predictor for prognosis and promotes cell growth in oral squamous cell carcinoma. Oncol. Lett. 2019, 17, 951-957. [CrossRef] [PubMed]

127. Chen, Z.F.; Wang, Y.; Sun, L.L.; Ding, S.Y.; Jinag, H. LncRNA SNHG20 enhances the progression of oral squamous cell carcinoma by regulating the miR-29a/DIXDC1/Wnt regulatory axis. Eur. Rev. Med. Pharmacol. Sci. 2020, 24, 5436-5445. [PubMed]

128. Lu, N.; Yin, Y.; Yao, Y.; Zhang, P. SNHG3/miR-2682-5p/HOXB8 promotes cell proliferation and migration in oral squamous cell carcinoma. Oral Dis. 2020. [CrossRef] [PubMed]

129. Yang, C.-M.; Wang, T.-H.; Chen, H.-C.; Li, S.-C.; Lee, M.-C.; Liou, H.-H.; Liu, P.-F.; Tseng, Y.-K.; Shiue, Y.-L.; Ger, L.-P.; et al. Aberrant DNA hypermethylation-silenced SOX21-AS1 gene expression and its clinical importance in oral cancer. Clin. Epigenetics 2016, 8, 129. [CrossRef]

130. Jin, N.; Jin, N.; Bu, W.; Li, X.; Liu, L.; Wang, Z.; Tong, J.; Li, D. Long non-coding RNA TIRY promotes tumor metastasis by enhancing epithelial-to-mesenchymal transition in oral cancer. Exp. Biol Med. 2020, 245, 585-596. [CrossRef]

131. Liang, S.; Zhang, S.; Wang, P.; Yang, C.; Shang, C.; Yang, J.; Wang, J. LncRNA, TUG1 regulates the oral squamous cell carcinoma progression possibly via interacting with $\mathrm{Wnt} / \beta$-catenin signaling. Gene 2017, 608, 49-57. [CrossRef]

132. Fang, Z.; Zhao, J.; Xie, W.; Sun, Q.; Wang, H.; Qiao, B. LncRNA UCA1 promotes proliferation and cisplatin resistance of oral squamous cell carcinoma by sunppressing miR-184 expression. Cancer Med. 2017, 6, 2897-2908. [CrossRef] [PubMed]

133. Duan, Q.; Xu, M.; Wu, M.; Zhang, X.; Gan, M.; Jiang, H. Long noncoding RNA UCA1 promotes cell growth, migration, and invasion by targeting miR-143-3p in oral squamous cell carcinoma. Cancer Med. 2020, 9, 3115-3129. [CrossRef] [PubMed]

134. Wang, J.; Li, L.; Wu, K.; Ge, W.; Zhang, Z.; Gong, L.; Yuan, D. Knockdown of long noncoding RNA urothelial cancer-associated 1 enhances cisplatin chemosensitivity in tongue squamous cell carcinoma cells. Pharmazie 2016, 71, 598-602. [PubMed] 
135. Yang, Y.T.; Wang, Y.F.; Lai, J.Y.; Shen, S.Y.; Wang, F.; Kong, J.; Zhang, W.; Yang, H.Y. Long non-coding RNA UCA1 contributes to the progression of oral squamous cell carcinoma by regulating the WNT/ $\beta$-catenin signaling pathway. Cancer Sci. 2016, 107, 1581-1589. [CrossRef] [PubMed]

136. Sanchez-Vega, F.; Mina, M.; Armenia, J.; Chatila, W.K.; Luna, A.; La, K.C.; Dimitriadoy, S.; Liu, D.L.; Kantheti, H.S.; Saghafinia, S.; et al.; Oncogenic Signaling Pathways in The Cancer Genome Atlas. Cell 2018, 173, 321-337. [CrossRef] [PubMed]

137. Noguti, J.; De Moura, C.F.G.; Hossaka, T.A.; Franco, M.; Oshima, C.T.F.; Dedivitis, R.A.; Ribeiro, D.A. The Role of Canonical WNT Signaling Pathway in Oral Carcinogenesis: A Comprehensive Review. Anticancer. Res. 2012, 32, 873-878. [PubMed]

138. Zhan, T.; Rindtorff, N.; Boutros, M. Wnt signaling in cancer. Oncogene 2017, 36, 1461-1473. [CrossRef]

139. Lyu, X.; Li, J.; Yun, X.; Huang, R.; Deng, X.; Wang, Y.; Chen, Y.; Xiao, G. miR-181a-5p, an inducer of Wnt-signaling, facilitates cell proliferation in acute lymphoblastic leukemia. Oncol Rep. 2017, 37, 1469-1476. [CrossRef]

140. Custódio, M.; Biddle, A.; Tavassoli, M. Portrait of a CAF: The story of cancer-associated fibroblasts in head and neck cancer. Oral Oncol. 2020, 110, 104972. [CrossRef]

141. Ding, Y.; Xi, Y.; Chen, T.; Wang, J.-y.; Tao, D.-l.; Wu, Z.-L.; Li, Y.-p.; Li, C.; Zeng, R.; Li, L. Caprin-2 enhances canonical Wnt signaling through regulating LRP5/6 phosphorylation. J. Cell Biol. 2008, 182, 865-872. [CrossRef]

142. Harsha, C.; Banik, K.; Ang, H.L.; Girisa, S.; Vikkurthi, R.; Parama, D.; Rana, V.; Shabnam, B.; Khatoon, E.; Kumar, A.P.; et al. Targeting AKT/mTOR in Oral Cancer: Mechanisms and Advances in Clinical Trials. Int. J. Mol. Sci 2020, 21, 3285. [CrossRef]

143. Peng, W.X.; Koirala, P.; Mo, Y.Y. LncRNA-mediated regulation of cell signaling in cancer. Oncogene 2017, 36, 5661-5667. [CrossRef] [PubMed]

144. Alzahrani, A. PI3K/Akt/mTOR inhibitors in cancer: At the bench and bedside. Seminars Cancer Biol. 2019, 59, 125-132. [CrossRef] [PubMed]

145. Kim, Y.C.; Guan, K.L. mTOR: A pharmacologic target for autophagy regulation. J. Clin. Invest. 2015, 125, 25-32. [CrossRef]

146. Siegel, P.M.; Massagué, J. Cytostatic and apoptotic actions of TGF-beta in homeostasis and cancer. Nat. Rev. Cancer 2003, 3 , 807-821. [CrossRef]

147. Papoutsoglou, P.; Moustakas, A. Long non-coding RNAs and TGF- $\beta$ signaling in cancer. Cancer Sci. 2020, $111,2672-2681$. [CrossRef] [PubMed]

148. FDA-NIH Biomarker Working Group. BEST (Biomarkers, EndpointS, and other Tools) Resource; Food and Drug Administration (US), National Institutes of Health (US): Bethesda, MD, USA, 2016.

149. Jiang, M.C.; Ni, J.J.; Cui, W.Y.; Wang, B.Y.; Zhuo, W. Emerging roles of lncRNA in cancer and therapeutic opportunities. Am. J. Cancer Res. 2019, 9, 1354-1366.

150. Mazumder, S.; Datta, S.; Ray, J.G.; Chaudhuri, K.; Chatterjee, R. Liquid biopsy: miRNA as a potential biomarker in oral cancer. Cancer Epidemiol. 2019, 58, 137-145. [CrossRef] [PubMed]

151. Wu, C.; Simonetti, M.; Rossell, C.; Mignardi, M.; Mirzazadeh, R.; Annaratone, L.; Marchiò, C.; Sapino, A.; Bienko, M.; Crosetto, N.; et al. RollFISH achieves robust quantification of single-molecule RNA biomarkers in paraffin-embedded tumor tissue samples. Commun. Biol. 2018, 1, 209. [CrossRef]

152. Crosetto, N.; Bienko, M.; van Oudenaarden, A. Spatially resolved transcriptomics and beyond. Nat. Rev. Genet. 2015, 16, 57-66. [CrossRef]

153. Mathai, R.; Vidya, R.; Reddy, B.; Thomas, L.; Udupa, K.; Kolesar, J.; Rao, M. Potential Utility of Liquid Biopsy as a Diagnostic and Prognostic Tool for the Assessment of Solid Tumors: Implications in the Precision Oncology. J. Clin. Med. 2019, 8, 373. [CrossRef] [PubMed]

154. De Rubis, G.; Rajeev Krishnan, S.; Bebawy, M. Liquid Biopsies in Cancer Diagnosis, Monitoring, and Prognosis. Trends Pharmacol. Sci. 2019, 40, 172-186. [CrossRef] [PubMed]

155. Arantes, L.; De Carvalho, A.C.; Melendez, M.E.; Lopes Carvalho, A. Serum, plasma and saliva biomarkers for head and neck cancer. Expert Rev. Mol. Diagn. 2018, 18, 85-112. [CrossRef] [PubMed]

156. Lousada-Fernandez, F.; Rapado-Gonzalez, O.; Lopez-Cedrun, J.L.; Lopez-Lopez, R.; Muinelo-Romay, L.; Suarez-Cunqueiro, M.M. Liquid Biopsy in Oral Cancer. Int. J. Mol. Sci. 2018, 19, 1704. [CrossRef]

157. Wu, J.; Hu, S.; Zhang, L.; Xin, J.; Sun, C.; Wang, L.; Ding, K.; Wang, B. Tumor circulome in the liquid biopsies for cancer diagnosis and prognosis. Theranostics 2020, 10, 4544-4556. [CrossRef]

158. De Rubis, G.; Krishnan, S.R.; Bebawy, M. Circulating tumor DNA - Current state of play and future perspectives. Pharmacol. Res. 2018, 136, 35-44. [CrossRef]

159. Fan, C.; Wang, J.; Tang, Y.; Zhang, S.; Xiong, F.; Guo, C.; Zhou, Y.; Li, Z.; Li, X.; Li, Y.; et al. Upregulation of long non-coding RNA LOC284454 may serve as a new serum diagnostic biomarker for head and neck cancers. BMC Cancer 2020, 20, 917. [CrossRef] [PubMed]

160. Cristaldi, M.; Mauceri, R.; Di Fede, O.; Giuliana, G.; Campisi, G.; Panzarella, V. Salivary Biomarkers for Oral Squamous Cell Carcinoma Diagnosis and Follow-Up: Current Status and Perspectives. Front. Physiol. 2019, 10, 1476. [CrossRef]

161. Tang, H.; Wu, Z.; Zhang, J.; Su, B. Salivary lncRNA as a potential marker for oral squamous cell carcinoma diagnosis. Mol. Med. Rep. 2013, 7, 761-766. [CrossRef]

162. Blondal, T.; Jensby Nielsen, S.; Baker, A.; Andreasen, D.; Mouritzen, P.; Wrang Teilum, M.; Dahlsveen, I.K. Assessing sample and miRNA profile quality in serum and plasma or other biofluids. Methods 2013, 59, S1-S6. [CrossRef] 
163. Livak, K.J.; Wills, Q.F.; Tipping, A.J.; Datta, K.; Mittal, R.; Goldson, A.J.; Sexton, D.W.; Holmes, C.C. Methods for qPCR gene expression profiling applied to 1440 lymphoblastoid single cells. Methods 2013, 59, 71-79. [CrossRef] [PubMed]

164. Lohmann, S.; Herold, A.; Bergauer, T.; Belousov, A.; Betzl, G.; Demario, M.; Dietrich, M.; Luistro, L.; Poignee-Heger, M.; Schostack, K.; et al. Gene expression analysis in biomarker research and early drug development using function tested reverse transcription quantitative real-time PCR assays. Methods 2013, 59, 10-19. [CrossRef]

165. Supper, J.; Gugenmus, C.; Wollnik, J.; Drueke, T.; Scherf, M.; Hahn, A.; Grote, K.; Bretschneider, N.; Klocke, B.; Zinser, C.; et al. Detecting and visualizing gene fusions. Methods 2013, 59, S24-S28. [CrossRef]

166. Hiraga, C.; Yamamoto, S.; Hashimoto, S.; Kasahara, M.; Minamisawa, T.; Matsumura, S.; Katakura, A.; Yajima, Y.; Nomura, T.; Shiba, K. Pentapartite fractionation of particles in oral fluids by differential centrifugation. Sci. Rep. 2021, 11, 3326. [CrossRef]

167. Minotti, L.; Agnoletto, C.; Baldassari, F.; Corrà, F.; Volinia, S. SNPs and Somatic Mutation on Long Non-Coding RNA: New Frontier in the Cancer Studies? High Throughput 2018, 7, 34. [CrossRef]

168. Yuan, Z.; Yu, Y.; Zhang, B.; Miao, L.; Wang, L.; Zhao, K.; Ji, Y.; Wang, R.; Ma, H.; Chen, N.; et al. Genetic variants in lncRNA H19 are associated with the risk of oral squamous cell carcinoma in a Chinese population. Oncotarget 2018, 9, 23915-23922. [CrossRef]

169. Yu, A.-M.; Jian, C.; Yu, A.H.; Tu, M.-J. RNA therapy: Are we using the right molecules? Pharmacol. Ther. 2019, 196, 91-104. [CrossRef] [PubMed]

170. Liang, X.; Li, D.; Leng, S.; Zhu, X. RNA-based pharmacotherapy for tumors: From bench to clinic and back. Biomed. Pharmacother. 2020, 125, 109997. [CrossRef] [PubMed]

171. Robinson, J.G. Management of familial hypercholesterolemia: A review of the recommendations from the National Lipid Association Expert Panel on Familial Hypercholesterolemia. J. Manag. Care Pharm. 2013, 19, 139-149. [CrossRef] [PubMed]

172. Wood, H. FDA approves patisiran to treat hereditary transthyretin amyloidosis. Nat. Rev. Neurol. 2018, 14, 570. [CrossRef] 